\title{
Molecular Modeling and Spectroscopic Studies of Benzothiazole
}

\author{
V. Sathyanarayanmoorthi, ${ }^{1}$ R. Karunathan, ${ }^{1}$ and V. Kannappan ${ }^{2}$ \\ ${ }^{1}$ PG and Research Department of Physics, PSG College of Arts and Science, Coimbatore 641 014, India \\ ${ }^{2} P G$ and Research Department of Chemistry, Presidency College, Chennai 600 005, India
}

Correspondence should be addressed to V. Sathyanarayanmoorthi; sathyanarayanamoorthi@yahoo.co.in

Received 20 May 2013; Revised 23 July 2013; Accepted 26 July 2013

Academic Editor: Cengiz Soykan

Copyright (c) 2013 V. Sathyanarayanmoorthi et al. This is an open access article distributed under the Creative Commons Attribution License, which permits unrestricted use, distribution, and reproduction in any medium, provided the original work is properly cited.

\begin{abstract}
The Fourier Transform (FT) infrared and FT-Raman spectra of benzothiazole (BT) have been recorded and analyzed. The equilibrium geometry, bonding features, and harmonic vibrational frequencies have been investigated by ab initio and density functional theory (DFT) methods. The assignments of the vibrational spectra have been carried out. The computed optimized geometric bond lengths and bond angles show good agreement with experimental data of the title compound. The calculated HOMO and LUMO energies indicate that charge transfer occurs within the molecule. Stability of the molecule due to conjugative interactions arising from charge delocalization has been analyzed using natural bond orbital (NBO) analysis. The results show that the electron density (ED) in the $\sigma^{*}$ and $\pi^{*}$ antibonding orbital and second-order delocalization energies $E(2)$ confirm the occurrence of intramolecular charge transfer (ICT). The calculated results were applied to simulate infrared and Raman spectra BT which show good agreement with recorded spectra.
\end{abstract}

\section{Introduction}

Benzothiazole (BT) molecule contains a thiazole ring fused with benzene ring. Thiazole ring is a five-member ring consists of one nitrogen and one sulfur atom in the ring. Benzothiazole is thus a bicyclic aromatic ring system. A number of BT derivatives have been studied as central muscle relaxants and found to interfere with glutamate neurotransmission in biochemical, electrophysiological, and behavioral experiments [1]. Substituted benzothiazoles have been studied and found to have various chemical reactivity and biological activity. Benzothiazole ring is found to possess pharmacological activities such as antiviral [2], antibacterial [3], antimicrobial [4], and fungicidal activities [5]. They are also useful as antiallergic [6], antidiabeticantitumor [7], antitumor [8], anti-inflammatory [9], anthelmintic [10], and anti-HIV agents. Phenyl substituted benzothiazoles show antitumor activity [11-13] while condensed pyrimido benzothiazoles and benzothiazoloquinazolines show antiviral activity. Substituted 6-nitro- and 6-amino-benzothiazoles show antimicrobial activity.

Molecular spectroscopic methods, in particular, experimental IR and Raman spectroscopy, have been successfully employed for structural investigation of complex molecular compounds. These techniques are especially effective when used in combination with direct methods of structural analysis in hydrogen bond investigations. The aim of the present work is theoretical and experimental spectroscopic investigation of BT molecular structure to gain insight into the structure and physical properties of the molecular structure. The FT-IR and FT-Raman spectra were simulated and compared with experimental results. Ab initio and DFT calculations have been performed to support the wave number assignments.

\section{Methodology}

2.1. Experimental Details. The compound under investigation, namely, BT, is spectral grade purchased from M/S Aldrich Chemicals, USA, and it is used as such without further purification. The FT-IR spectrum of the compound was recorded in Perkin-Elmer Spectrometer in the range of 4000$100 \mathrm{~cm}^{-1}$ using $\mathrm{KBr}$ pellet technique. The spectral resolution is $0.1 \mathrm{~cm}^{-1}$. The FT-Raman spectrum of the compound was recorded in the BRUKER RFS 27 and Standalone FT-Raman 
Spectrometer in the frequency range $50-4000 \mathrm{~cm}^{-1}$. The Laser source is $\mathrm{Nd}$ : YAG laser source operating at $1064 \mathrm{~nm}$ line with $200 \mathrm{~mW}$ power. The spectra were recorded with scanning speed of $20 \mathrm{~cm}^{-1}$. The frequencies of all sharp bands are accurate to $\pm 1 \mathrm{~cm}^{-1}$.

2.2. Computational Details. The molecular geometry optimization and vibrational frequency calculations were carried out on benzothiazole, with GAUSSIAN 09W software package [14] HF functional $[15,16]$ combined with standard 6$311 \mathrm{G}$ and $6-311++\mathrm{G}(\mathrm{d}, \mathrm{p})$ basis set (referred to as "large" basis) and the density functional method used is B3LYP, that is, Becke's three-parameter hybrid functional with the LeeYang-Parr correlation functional method with 6-311++G (d, p). The harmonic vibrational frequencies calculated for BT at HF and B3LYP levels using the triple split valence basis set along with the diffuse and polarization functions. It may be pointed out that computed wave number corresponds to the isolated molecular state in the gaseous phase whereas the experimental wave numbers correspond to the solid state spectra. In order to evaluate the energetic behavior of the title compound, we carried out calculations in vacuo and in organic solvent (ethanol). The energies of important molecular orbitals of BT, the highest occupied MOs (HOMO), and the lowest unoccupied MOs (LUMO) were calculated using HF/6-311++G (d, p) method. NBO analysis has been performed on the BT molecule at the $\mathrm{HF} / 6-311++\mathrm{G}(\mathrm{d}, \mathrm{p})$ and B3LYP/6-311++G (d, p) level in order to elucidate the intramolecular, rehybridization, and delocalization of electron density within the molecule. The result of interaction is a loss of occupancy from the density of electron in NBO of the idealized Lewis structure into an empty non-Lewis orbital. For each donor $(i)$ and acceptor $(j)$, the stabilization energy $E(2)$ associated with the delocalization $i \rightarrow j$ is estimated as

$$
E(2)=-n_{\sigma} \frac{\langle\sigma|F| \sigma\rangle^{2}}{\varepsilon_{\sigma}^{*}-\varepsilon_{\sigma}}=-n_{\sigma} \frac{F_{i j}{ }^{2}}{\Delta E},
$$

where $\langle\sigma|F| \sigma\rangle^{2}$ or $F_{i j}{ }^{2}$ is the Fock matrix element $i$ and $j$ NBO orbital's, $\varepsilon_{\sigma}^{*}$ and $-\varepsilon_{\sigma}$ are the energies of $\sigma$ and $\sigma^{*}$ NBOs, and $n_{\sigma}$ is the population of the donor $\sigma$ orbital. Zero point vibrational energy, internal energy and its translational, rotational, and vibrational contributions, entropy, and heat capacity of BT are computed through the calculation of partition functions [17-19].

\section{Results and Discussion}

3.1. Molecular Geometry. The optimized geometry of the molecule under investigation with IUPAC numbering scheme for the atoms is presented in Figure 1. The data of structural parameters obtained by ab initio method as compared to density functional theory for benzothiazole are reported in Table 1. The comparative graphs of bond lengths and bond angles of the title molecule are presented in Figure 2 . From the computed values, it is found that most of the optimized bond lengths are slightly larger than the experimental values, this may be due to the fact that theoretical calculations

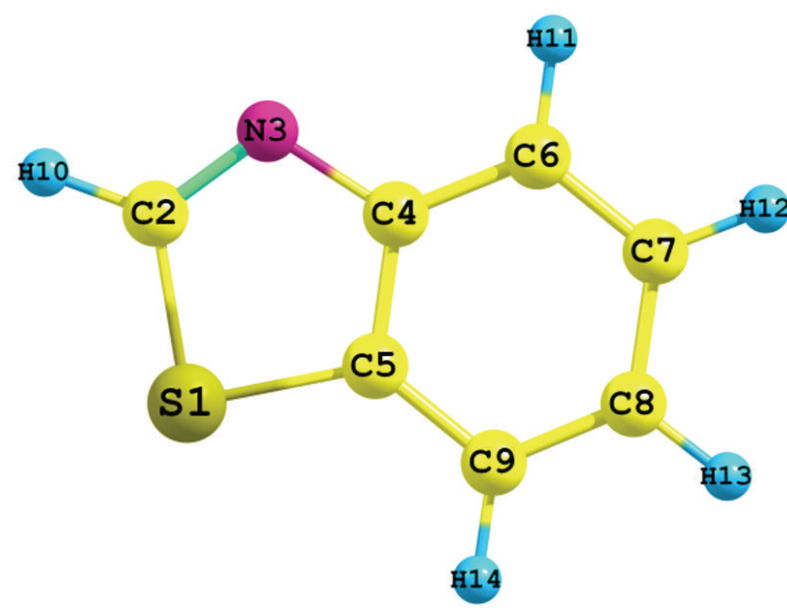

Figure 1: Optimized structure of benzothiazole.

belong to isolated molecules in gaseous phase and the experimental results belong to molecules in solid state. Comparing bond angles and lengths obtained by B3LYP method with those obtained by HF, as a whole the values got by the former are higher than those obtained be the later method. It may be pointed out that the values calculated by B3LYP method correlate satisfactorily with the experimental data. From the data shown in Table 1, it is seen that both HF and DFT (B3LYP/6-311++G (d, p)) levels of theory in general estimate the same values of some bond lengths and bond angles. It is well known that HF methods underestimate and DFT method overestimates bond lengths, particularly the $\mathrm{C}-\mathrm{H}$ bond lengths $[20,21]$. This theoretical pattern is also found for benzothiazole molecule.

The carbon-carbon bonds in benzene are not of equal length which is justified by the presence of fused thiazole ring. However, the differences between the six $\mathrm{C}-\mathrm{C}$ distances are small. The longest bond distance in $\mathrm{C} 4-\mathrm{C} 5$ bond is due to the fusion of thiazole moiety at these carbons. Comparing the bond distances of the hetero aromatic ring, it is found that the bond distances in hetero aromatic ring differ significantly from each other due to the difference in electronegativities of the bonded atoms. The S1-C2 bond distance is the longest $(1.7651 \AA)$ while the $\mathrm{C} 2-\mathrm{N} 3$ is the shortest $(1.2874 \AA)$. The longest $\mathrm{S} 1-\mathrm{C} 2$ distance attributes the pure single bond character. The $\mathrm{C} 5-\mathrm{S} 1$ and $\mathrm{C} 2-\mathrm{S} 1$ bond distances of BT determined by B3LYP/6-311++G (d, p) method are $1.75 \AA$ and $1.7651 \AA$, respectively, in between the $1.81 \AA$ average distance for a carbon-sulfur bond and the $1.61 \AA$ which indicate that the actual bond order is between one and two which is due to conjugative effect in benzothiazole. Due to ring strain the C2$\mathrm{N} 3$ double bond distance is $1.268 \AA, 1.268 \AA, 1.263 \AA$ in $\mathrm{HF}$, and $1.2874 \AA$ for B3LYP/6-311++G (d, p) bigger than single bond $\mathrm{C} 2-\mathrm{H} 10$. With the electron donating substituents on the benzene ring, the symmetry of the ring is distorted, yielding ring angles smaller than $120^{\circ}$ at the point of substitution and slightly larger than $120^{\circ}$ at the ortho- and metapositions [22]. It is observed that in BT molecule the bond angle at the point of substitution $\mathrm{C} 4-\mathrm{C} 5-\mathrm{C} 9$ is $118.7^{\circ}$ in $\mathrm{HF}$ and $118.9^{\circ}$ 


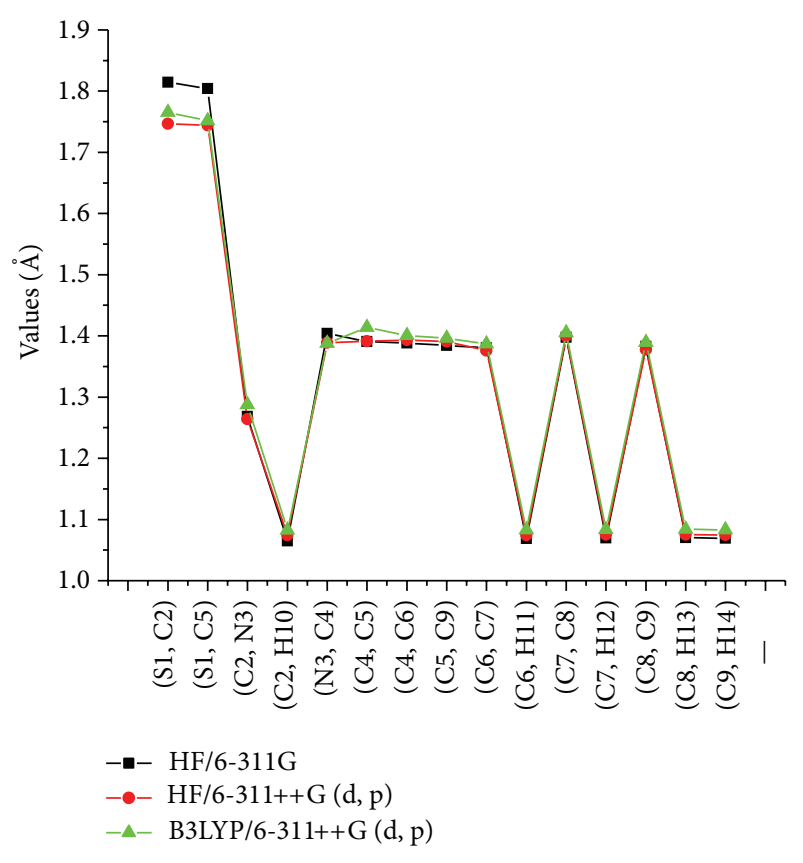

(a)

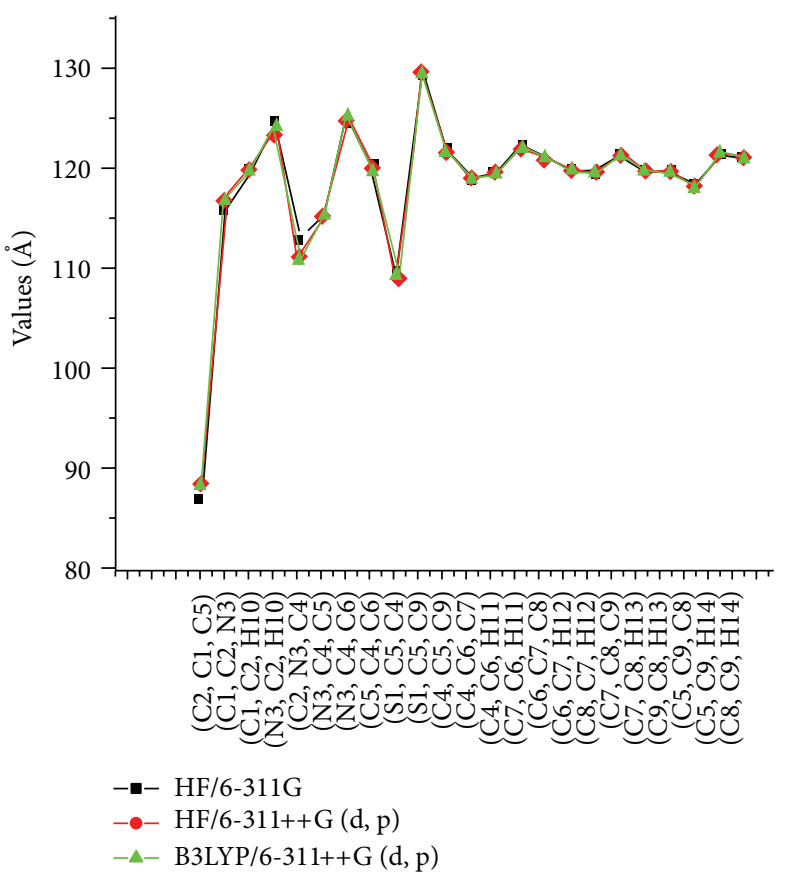

(b)

FIGURE 2: Bond length and bond angle difference between theoretical (HF and DFT) approaches.

in DFT while the bond angles in at ortho to the substituted carbon, C6-C7-C8 position is found to be $120.8677,120.908$ degree at HF and DFT respectively. This may be due to mesomeric effect of the thiazole ring. The meta position angle C7-C8-C9 is greater than $120^{\circ}$ and is found to be $120.91^{\circ}$, $121.078^{\circ}$. More distortion in bond parameters is observed in the heteroring than in the benzene ring. The variation in bond angle depends on the electronegativity of the central atom, the presence of lone pair of electrons, and the conjugation of the double bonds. If the electro negativity of the central atom is less, the bond angle decreases. Thus, the bond angle C5-S1-C2 is very less $\left(88.2122^{\circ}, 88.2011^{\circ}\right)$ than the bond angle $\mathrm{C} 8-\mathrm{N} 3-\mathrm{C} 2\left(110.755^{\circ}, 110.742^{\circ}\right)$ which is due to the fact that electronegativity of nitrogen is greater than sulfur.

3.2. Vibrational Assignments. The BT molecule consists of 14 atoms and so it has 36 normal vibrational modes. The observed vibrational assignments and analysis of BT are discussed in terms of fundamental bands. The harmonic vibrational frequencies calculated for BT at HF and B3LYP levels along with the observed FT-IR and FT-Raman frequencies for various modes of vibrations have been presented in Table 2 . The comparative values of IR and Raman intensities are given in Table 3. The recorded FT-IR and FT-Raman spectra of BT are given in in Figures 3(a) and 3(b) respectively. Theoretical FT-IR and FT-Raman spectra are reported in Figures 4 and 5, respectively. It may be pointed out here that computed wave numbers correspond to the isolated molecular state in the gas phase whereas the experimental wave numbers correspond to the solid state spectra. The calculated vibrational frequencies using different methods are compared with experimentally observed values. The calculated vibrational wave numbers are consistent with the experimental results. Few bands predicted theoretically in FT-IR spectra were not observed in the experimental spectrum of BT molecule may be due to their very weak intensity.

3.2.1. $C-H$ Stretching. Aromatic compounds commonly exhibit multiple weak bands in the region $3100-3000 \mathrm{~cm}^{-1}$ [23-25] due to aromatic $\mathrm{C}-\mathrm{H}$ stretching vibrations. In the present case, the $\mathrm{C}-\mathrm{H}$ stretching vibrations are captured at $3061,3150 \mathrm{~cm}^{-1}$ in (mode no. 32, 33) FT-IR spectrum and corresponding Raman spectrum observed at $3063 \mathrm{~cm}^{-1}$. The aromatic $\mathrm{C}-\mathrm{H}$ in-plane bending modes of benzene and its derivatives are observed in the region $1300-1000 \mathrm{~cm}^{-1}$. The C-H out-of-plane bending modes [26-29] are usually of medium intensity and absorption in the region 950$600 \mathrm{~cm}^{-1}$. In the case of BT, the bands observed at 1069, 1124, 1157,1198 , and $1264 \mathrm{~cm}^{-1}$ (mode no. 17, 19, 20, 21, and 22) in IR and at $1292 \mathrm{~cm}^{-1}$ in Raman spectra are assigned to the $\mathrm{C}-\mathrm{H}$ in-plane bending vibrations. The $\mathrm{C}-\mathrm{H}$ out of plane bending mode of benzene derivatives is observed in the region 1000$600 \mathrm{~cm}^{-1}$. The aromatic $\mathrm{C}-\mathrm{H}$ out of plane bending vibrations of BT are assigned to the medium to weak bands observed at 1014 and $978 \mathrm{~cm}^{-1}$ (mode no. 14, 15) in the infrared spectrum and $1016 \mathrm{~cm}^{-1}$ in Raman spectrum. The aromatic C-H inplane and out of plane bending vibrations have substantial overlapping with the ring $\mathrm{C}-\mathrm{C}-\mathrm{C}$ in-plane and out of plane bending modes, respectively.

3.2.2. C-S Stretching. The C-S and S-H bonds are highly polarizable and hence exhibit stronger spectral activity. The C-S stretching vibration is expected in the region 710$685 \mathrm{~cm}^{-1}[30]$. The C-S stretching vibrations were observed 
TABLE 1: Optimized some geometrical parameters of benzothiazole, bond length $(\AA)$, and bond angles $\left(^{\circ}\right)$.

\begin{tabular}{|c|c|c|c|c|}
\hline Parameters & $\mathrm{HF} / 6-31 \mathrm{G}$ & $\mathrm{HF} / 6-311 \mathrm{G}$ & $\mathrm{HF} / 6-311++\mathrm{G}$ & B3LYP/6-311G \\
\hline \multicolumn{5}{|l|}{ Bond length } \\
\hline$(\mathrm{S} 1, \mathrm{C} 2)$ & 1.8159 & 1.8146 & 1.7464 & 1.7651 \\
\hline (S1, C5) & 1.8096 & 1.8043 & 1.7443 & 1.7518 \\
\hline$(\mathrm{C} 2, \mathrm{~N} 3)$ & 1.2688 & 1.2683 & 1.2638 & 1.2874 \\
\hline$(\mathrm{C} 2, \mathrm{H} 10)$ & 1.0665 & 1.0647 & 1.0744 & 1.0827 \\
\hline$(\mathrm{N} 3, \mathrm{C} 4)$ & 1.4031 & 1.404 & 1.3886 & 1.3877 \\
\hline$(\mathrm{C} 4, \mathrm{C} 5)$ & 1.3926 & 1.391 & 1.3912 & 1.4139 \\
\hline$(\mathrm{C} 4, \mathrm{C} 6)$ & 1.3887 & 1.3882 & 1.3932 & 1.4008 \\
\hline (C5, C9) & 1.385 & 1.3844 & 1.3907 & 1.3962 \\
\hline$(\mathrm{C} 6, \mathrm{C} 7)$ & 1.3811 & 1.3803 & 1.3761 & 1.3866 \\
\hline (C6, H11) & 1.0713 & 1.0689 & 1.0743 & 1.0832 \\
\hline$(\mathrm{C} 7, \mathrm{C} 8)$ & 1.3975 & 1.3976 & 1.3994 & 1.405 \\
\hline$(\mathrm{C} 7, \mathrm{H} 12)$ & 1.0723 & 1.07 & 1.075 & 1.0838 \\
\hline$(\mathrm{C} 8, \mathrm{C} 9)$ & 1.3843 & 1.383 & 1.3774 & 1.3893 \\
\hline$(\mathrm{C} 8, \mathrm{H} 13)$ & 1.0726 & 1.0703 & 1.0751 & 1.0839 \\
\hline$(\mathrm{C} 9, \mathrm{H} 14)$ & 1.0715 & 1.0694 & 1.0746 & 1.0832 \\
\hline \multicolumn{5}{|l|}{ Bond angle } \\
\hline$(\mathrm{C} 2, \mathrm{C} 1, \mathrm{C} 5)$ & 86.7846 & 86.8578 & 88.2122 & 88.2011 \\
\hline$(\mathrm{C} 1, \mathrm{C} 2, \mathrm{~N} 3)$ & 115.703 & 115.6631 & 116.9227 & 116.6919 \\
\hline$(\mathrm{C} 1, \mathrm{C} 2, \mathrm{H} 10)$ & 119.792 & 119.7907 & 119.7167 & 119.3151 \\
\hline$(\mathrm{N} 3, \mathrm{C} 2, \mathrm{H} 10)$ & 124.5047 & 124.5462 & 123.3605 & 123.993 \\
\hline$(\mathrm{C} 2, \mathrm{~N} 3, \mathrm{C} 4)$ & 112.9102 & 112.8215 & 110.755 & 110.742 \\
\hline (N3, C4, C5) & 115.155 & 115.1091 & 115.1782 & 115.2284 \\
\hline (N3, C4, C6) & 124.5797 & 124.5766 & 124.855 & 125.1777 \\
\hline$(\mathrm{C} 5, \mathrm{C} 4, \mathrm{C} 6)$ & 120.2653 & 120.3142 & 119.9668 & 119.5939 \\
\hline$(\mathrm{S} 1, \mathrm{C} 5, \mathrm{C} 4)$ & 109.4469 & 109.5485 & 108.9318 & 109.1366 \\
\hline (S1, C5, C9) & 129.1903 & 129.1251 & 129.6054 & 129.4096 \\
\hline$(\mathrm{C} 4, \mathrm{C} 5, \mathrm{C} 9)$ & 121.3628 & 121.3263 & 121.4628 & 121.4538 \\
\hline$(\mathrm{C} 4, \mathrm{C} 6, \mathrm{C} 7)$ & 118.7264 & 118.7178 & 118.7551 & 118.9556 \\
\hline$(\mathrm{C} 4, \mathrm{C} 6, \mathrm{H} 11)$ & 119.3604 & 119.2699 & 119.5996 & 119.307 \\
\hline (C7, C6, H11) & 121.9132 & 122.0123 & 121.6452 & 121.7374 \\
\hline$(\mathrm{C} 6, \mathrm{C} 7, \mathrm{C} 8)$ & 120.6426 & 120.6135 & 120.8677 & 120.908 \\
\hline (C6, C7, H12) & 119.8217 & 119.8388 & 119.7498 & 119.6972 \\
\hline (C8, C7, H12) & 119.5357 & 119.5477 & 119.3825 & 119.3948 \\
\hline$(\mathrm{C} 7, \mathrm{C} 8, \mathrm{C} 9)$ & 120.9529 & 120.9354 & 120.9119 & 121.0788 \\
\hline (C7, C8, H13) & 119.5983 & 119.6269 & 119.5658 & 119.5843 \\
\hline$(\mathrm{C} 9, \mathrm{C} 8, \mathrm{H} 13)$ & 119.4487 & 119.4377 & 119.5223 & 119.3369 \\
\hline$(\mathrm{C} 5, \mathrm{C} 9, \mathrm{C} 8)$ & 118.0499 & 118.0927 & 118.0357 & 118.0099 \\
\hline (C5, C9, H14) & 121.1939 & 121.1702 & 121.132 & 121.2411 \\
\hline$(\mathrm{C} 8, \mathrm{C} 9, \mathrm{H} 14)$ & 120.7561 & 120.7371 & 120.8323 & 120.749 \\
\hline
\end{tabular}

in the region $609-716 \mathrm{~cm}^{-1}$ for 2-mercapto benzothiazole [31]. The calculated values of the vibrations range from $572 \mathrm{~cm}^{-1}$ to $876 \mathrm{~cm}^{-1}$. For 2-mercaptobenzoxazole [32], the calculated values of the vibrations range from $579 \mathrm{~cm}^{-1}$ to $892 \mathrm{~cm}^{-1}$ and the observed C-S stretching vibration is $954 \mathrm{~cm}^{-1}$. In our title molecule, the $\mathrm{C}-\mathrm{S}$ stretching is observed at 667 and $799 \mathrm{~cm}^{-1}$ (mode no. 9, 11) in FT-IR. The FT-Raman spectrum value at $801 \mathrm{~cm}^{-1}$ as a medium band is assigned to $\mathrm{C}-\mathrm{S}$ stretching vibration. The calculated frequencies of $668,652,600$, and $626 \mathrm{~cm}^{-1}$ exactly correlate with experimental observation as well as the literature data. The $\mathrm{C}-\mathrm{S}$ vibration is a pure mode as evident from Table 2 . The inplane and out-of-plane C-S stretching vibration also exactly correlates with experimental observations.

3.2.3. $C=N$ Vibrations. The $\mathrm{C}=\mathrm{N}$ stretching vibrations [33$36]$ are observed in the range $1672-1566 \mathrm{~cm}^{-1}$. Varsanyi [37] has suggested that an IR band at $1626 \mathrm{~cm}^{-1}$ for $\mathrm{C}=\mathrm{N}$ stretching and Raman frequency is assigned to the $\mathrm{C}=\mathrm{N}$ stretching vibration of benzothizaole [38]. The respective 
TABLE 2: Comparison of the experimental (FT-IR and FT-Raman) and theoretical harmonic wave numbers $\left(\mathrm{cm}^{-1}\right.$ ) of benzothiazole calculated by HF, B3LYP with 6-311++G(d, p) basis set.

\begin{tabular}{|c|c|c|c|c|c|c|}
\hline \multirow{2}{*}{ Modes no. } & \multicolumn{2}{|c|}{ Experimental } & \multirow{2}{*}{$6-311 G$} & \multirow{2}{*}{$6-311++G$} & \multirow{2}{*}{$\begin{array}{c}\text { B3LYP } \\
6-311++G\end{array}$} & \multirow{2}{*}{ Assignment } \\
\hline & IR & Raman & & & & \\
\hline 1. & & 71.44 & 185.6993 & 221.8993 & 158.2282 & $\mathrm{C}-\mathrm{H}-$ out of plane bending \\
\hline 2. & & 210.04 & 244.1506 & 259.6877 & 225.0702 & $\mathrm{C}-\mathrm{H}-$ out of plane bending \\
\hline 3. & & 352.91 & 372.6441 & 373.5584 & 341.0859 & Ring stretching \\
\hline 4. & & 424.17 & 426.2948 & 414.1324 & 350.0611 & $\mathrm{~N}-\mathrm{CH}$ Wagging \\
\hline 5. & & & 471.7758 & 467.2944 & 429.3019 & $\mathrm{C}-\mathrm{S}-\mathrm{C}$ in plane bending \\
\hline 6. & 531 & 505.08 & 520.8227 & 507.0766 & 451.8357 & $\mathrm{C}-\mathrm{C}-\mathrm{C}-$ out of plane bending \\
\hline 7. & 585 & & 541.0727 & 532.2922 & 481.3446 & $\mathrm{C}-\mathrm{C}-\mathrm{C}-$ out of plane bending \\
\hline 8. & & & 623.6493 & 608.7293 & 560.6751 & $\mathrm{C}-\mathrm{C}-\mathrm{C}-$ out of plane bending \\
\hline 9. & 667 & & 668.2929 & 652.4117 & 600.4245 & C-S Stretching \\
\hline 10. & 769 & 706.88 & 730.3856 & 717.6507 & 666.7194 & C-C-C Ring breathing \\
\hline 11. & 799 & 801.01 & 777.8919 & 759.172 & 709.0033 & C-S Stretching \\
\hline 12. & 828 & & 846.4841 & 825.1871 & 754.3702 & Thiazole Ring Stretching \\
\hline 13. & 873 & & 877.3007 & 872.0681 & 804.3435 & $\mathrm{C}-\mathrm{C}-\mathrm{C}-$ in plane bending \\
\hline 14. & 978 & & 974.2327 & 929.8297 & 827.145 & $\mathrm{C}-\mathrm{H}-$ out of plane bending \\
\hline 15. & 1014 & 1015.54 & 1025.745 & 970.2269 & 875.2731 & $\mathrm{C}-\mathrm{H}-$ out of plane bending \\
\hline 16. & & & 1058.5012 & 1030.8954 & 922.7485 & C-S-Stretching \\
\hline 17. & 1069 & & 1085.408 & 1053.4724 & 985.3864 & $\mathrm{C}-\mathrm{H}-\mathrm{in}$ plane bending \\
\hline 18. & & & 1110.2525 & 1069.5475 & 993.4765 & $\mathrm{C}-\mathrm{H}-$ in plane bending \\
\hline 19. & 1124 & 1124.88 & 1124.8897 & 1096.4601 & 1015 & $\mathrm{C}-\mathrm{H}-$ in plane bending \\
\hline 20. & 1157 & & 1166.0662 & 1125.1724 & 1027.9394 & $\mathrm{C}-\mathrm{H}-$ in plane bending \\
\hline 21. & 1198 & 1197.98 & 1194.0921 & 1154.4126 & 1092.4829 & $\mathrm{C}-\mathrm{H}-$ in plane bending \\
\hline 22. & 1264 & & 1203.5496 & 1178.2819 & 1126.6974 & $\mathrm{C}-\mathrm{H}-$ in plane bending \\
\hline 23. & 1292 & 1291.66 & 1243.9149 & 1216.6827 & 1153.3509 & C-C Stretching \\
\hline 24. & 1315 & 1316.01 & 1338.3513 & 1309.6226 & 1244.4551 & C-C-Stretching \\
\hline 25. & 1423 & & 1394.2405 & 1364.2723 & 1268.7322 & C-C-Stretching \\
\hline 26. & 1454 & 1424.58 & 1427.192 & 1397.859 & 1275.7476 & C-C-Stretching \\
\hline 27. & 1490 & 1468.87 & 1575.3975 & 1556.5462 & 1440.267 & $\mathrm{C}-\mathrm{H}$ in plane bending \\
\hline 28. & 1556 & 1557.01 & 1585.4282 & 1562.2713 & 1444.1304 & $\mathrm{C}-\mathrm{H}$ in plane bending \\
\hline 29. & 1592 & & 1654.5209 & 1642.2366 & 1519.1381 & $\mathrm{C}=\mathrm{N}$ Stretching \\
\hline 30. & 1657 & & 1663.2985 & 1653.9474 & 1535.0676 & C-C-C Stretching \\
\hline 31. & 1692 & & 1716.6492 & 1703.8545 & 1628.1791 & $\mathrm{C}=\mathrm{N}$ Stretching \\
\hline 32. & 3061 & 3063.23 & 3070.1368 & 3105.7742 & 3028.6049 & $\mathrm{C}-\mathrm{H}$ Stretching \\
\hline 33. & 3150 & & 3082.2096 & 3116.571 & 3036.013 & C-H Stretching \\
\hline 34. & & & 3085.3847 & 3118.2409 & 3037.4297 & C-H Stretching \\
\hline 35. & & & 3094.2296 & 3126.9054 & 3046.2331 & $\mathrm{C}-\mathrm{H}$ Stretching \\
\hline 36. & & & 3105.5365 & 3135.3642 & 3054.1799 & C-H Stretching \\
\hline
\end{tabular}

bands occurring at 1692 and $1592 \mathrm{~cm}^{-1}$ (mode no. 29, 31) in IR spectra is assigned to the $\mathrm{C}=\mathrm{N}$ stretching vibration for $\mathrm{BT}$ molecule. The bands corresponding to the $\mathrm{C}-\mathrm{C}-\mathrm{C}$ and $\mathrm{C}-\mathrm{S}-$ $\mathrm{C}$ in-plane and out of plane bending modes of BT are presented in Table 3. Normal coordinate analysis shows that significant mixing of $\mathrm{C}-\mathrm{C}-\mathrm{C}$ in-plane bending with $\mathrm{C}-\mathrm{H}$ inplane bending occurs. Similarly, the skeletal out of plane bending modes are overlapped with $\mathrm{C}-\mathrm{H}$ out of plane bending modes significantly. The theoretically calculated values of
$\mathrm{C}=\mathrm{N}$ Stretching vibrations are in the region 1717,1704 , and $1629 \mathrm{~cm}^{-1}$.

3.2.4. Ring Vibrations. The carbon-carbon stretching modes of the benzene ring are expected to be in the range from 1650 to $1200 \mathrm{~cm}^{-1}$ and are usually not very sensitive to substitution by small substituents, but heavy halogens diminish the frequency $[39,40]$. In the Raman spectrum of BT, the carboncarbon stretching bands appeared at 1596, 1575, 1478, and 
TABLE 3: Comparative values of IR and Raman intensities between HF/6-311G++(d, p) and B3LYP/6-311G++(d, p) of benzothiazole.

\begin{tabular}{|c|c|c|c|c|c|}
\hline \multicolumn{2}{|c|}{$\mathrm{HF} / 6-311 \mathrm{G}(\mathrm{d}, \mathrm{p})$} & \multicolumn{2}{|c|}{$\mathrm{HF} / 6-311++\mathrm{G}(\mathrm{d}, \mathrm{p})$} & \multicolumn{2}{|c|}{ B3LYP/6-311++G $(d, p)$} \\
\hline IR intensity & Raman intensity & IR intensity & Raman intensity & IR intensity & Raman intensity \\
\hline 8.55 & 31.44 & 7.69 & 16.97 & 12.75 & 32.04 \\
\hline 0.87 & 10.21 & 1.58 & 7.93 & 1.23 & 7.36 \\
\hline 1.11 & 15.00 & 1.26 & 14.27 & 1.19 & 13.42 \\
\hline 14.98 & 26.31 & 17.53 & 25.42 & 22.89 & 22.11 \\
\hline 1.14 & 24.06 & 0.97 & 16.81 & 1.513 & 19.92 \\
\hline 12.88 & 9.86 & 11.17 & 7.72 & 10.50 & 5.311 \\
\hline 0.17 & 6.11 & 2.07 & 3.90 & 1.79 & 4.11 \\
\hline 6.63 & 3.63 & 5.86 & 3.62 & 6.73 & 2.43 \\
\hline 3.04 & 2.78 & 4.66 & 2.08 & 4.05 & 2.15 \\
\hline 4.84 & 5.27 & 5.06 & 5.14 & 5.06 & 2.90 \\
\hline 16.16 & 8.09 & 14.71 & 9.23 & 18.48 & 11.02 \\
\hline 20.38 & 6.69 & 26.21 & 3.72 & 23.66 & 1.91 \\
\hline 14.24 & 3.81 & 15.91 & 3.61 & 10.31 & 3.08 \\
\hline 88.08 & 0.38 & 78.09 & 4.38 & 78.12 & 0.52 \\
\hline 11.60 & 18.23 & 24.84 & 13.09 & 17.20 & 4.92 \\
\hline 12.48 & 4.88 & 10.48 & 10.79 & 2.23 & 1.10 \\
\hline 15.42 & 2.25 & 16.04 & 6.34 & 10.29 & 9.35 \\
\hline 0.58 & 1.192 & 5.73 & 2.50 & 13.25 & 17.50 \\
\hline 12.94 & 2.06 & 7.02 & 1.59 & 1.43 & 1.99 \\
\hline 3.15 & 1.57 & 4.43 & 1.34 & 1.70 & 2.25 \\
\hline 2.39 & 0.65 & 0.82 & 0.11 & 7.34 & 18.81 \\
\hline 3.40 & 0.08 & 8.71 & 3.65 & 1.30 & 7.484 \\
\hline 12.76 & 5.03 & 16.28 & 9.62 & 8.45 & 1.82 \\
\hline 1.98 & 0.18 & 1.16 & 0.13 & 7.05 & 0.10 \\
\hline 0.07 & 2.50 & 1.02 & 2.27 & 16.98 & 4.84 \\
\hline 34.14 & 3.30 & 40.98 & 3.72 & 7.68 & 0.81 \\
\hline 27.04 & 0.98 & 14.87 & 1.57 & 8.36 & 1.87 \\
\hline 6.66 & 0.87 & 29.51 & 0.63 & 19.58 & 0.29 \\
\hline 10.29 & 9.44 & 13.58 & 13.94 & 9.66 & 13.7 \\
\hline 16.35 & 3.27 & 8.27 & 2.84 & 0.99 & 1.65 \\
\hline 98.69 & 9.45 & 112.55 & 19.48 & 108.78 & 11.77 \\
\hline 0.30 & 2.40 & 0.15 & 1.97 & 0.06 & 2.14 \\
\hline 7.94 & 6.26 & 4.21 & 5.60 & 4.37 & 10.42 \\
\hline 13.26 & 10.55 & 9.96 & 9.44 & 3.21 & 6.44 \\
\hline 23.65 & 2.74 & 14.21 & 2.44 & 10.14 & 3.24 \\
\hline 23.43 & 15.30 & 12.95 & 13.86 & 9.55 & 16.75 \\
\hline
\end{tabular}

$1209 \mathrm{~cm}^{-1}$. The corresponding $\mathrm{C}-\mathrm{C}$ stretching modes are observed in the infrared spectrum at 1454, 1423, 1315, and $1292.31 \mathrm{~cm}^{-1}$ (mode no. 23, 24, 25, and 26). The theoretically calculated values are calculated at 1604, 1602, 1486, 1454, 1328, and $1304 \mathrm{~cm}^{-1}$ and these values show excellent agreement with experimental data.

The infrared band at $873 \mathrm{~cm}^{-1}$ and two Raman bands at 1000 and $700 \mathrm{~cm}^{-1}$ (mode no. 13) are assigned to $\mathrm{C}-\mathrm{C}-\mathrm{C}$ inplane bending vibrations of BT. The $\mathrm{C}-\mathrm{C}$ in-plane bending vibrations appeared as the combination vibrations with $\mathrm{C}-$ $\mathrm{H}$ in-plane bending vibrations. The bands assigned to $\mathrm{C}-$ $\mathrm{C}-\mathrm{C}$ out-of-plane bending vibrations are observed at 585, $531 \mathrm{~cm}^{-1}$ in (mode no. 6,7) FTIR spectrum and $505 \mathrm{~cm}^{-1}$ in Raman spectrum for BT. The ring breathing vibrations are generally very strong in Raman spectrum. This mode is found in the region $1100-1000 \mathrm{~cm}^{-1}$ for a heavy substituted compound and is strongly Raman active. This is confirmed by the very weak intense Raman band at $706 \mathrm{~cm}^{-1}$ which is supported by computed results. The ring stretching mode is captured at $372.6441,373.5584$, and $341.0859 \mathrm{~cm}^{-1}$ (mode no. 3) in HF/6-311++G (d, p) and B3LYP/6-311++G (d, p) for benzothiazole molecule. Comparison of IR intensities and Raman intensities calculated (Table 3 ) by HF and DFT (B3LYP) at 6-311+G (d, p) level with experimental values exposes the variation of IR intensities and Raman intensities. Most of the cases, the values of IR intensities by HF are found 


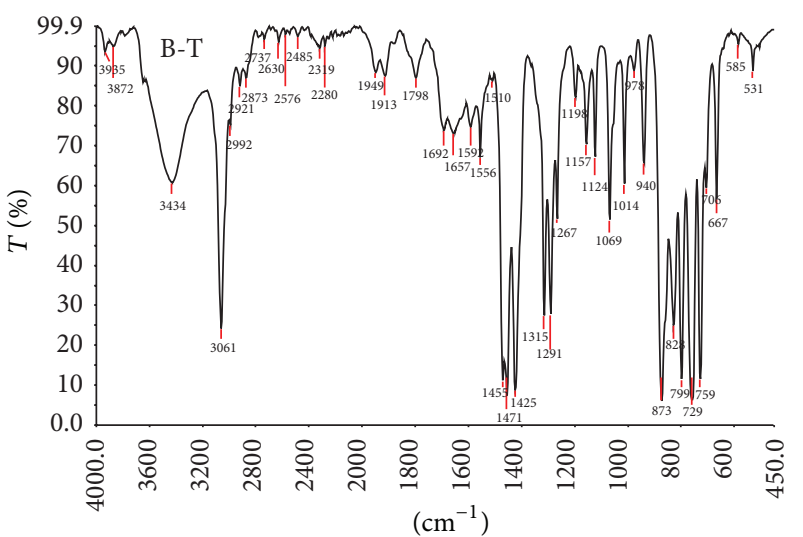

(a)

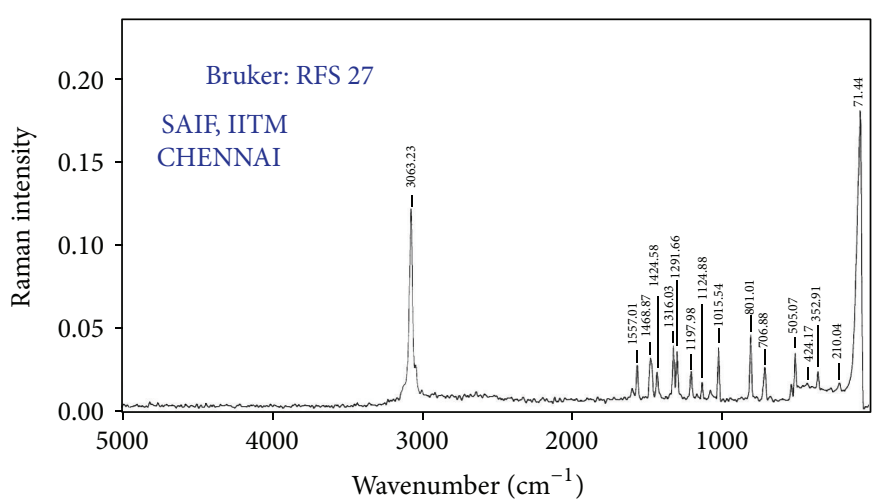

(b)

FIgURE 3: Experimental FT-IR and FT-Raman spectrum of benzothiazole.

$\mathrm{HF} / 6-311 \mathrm{G}$

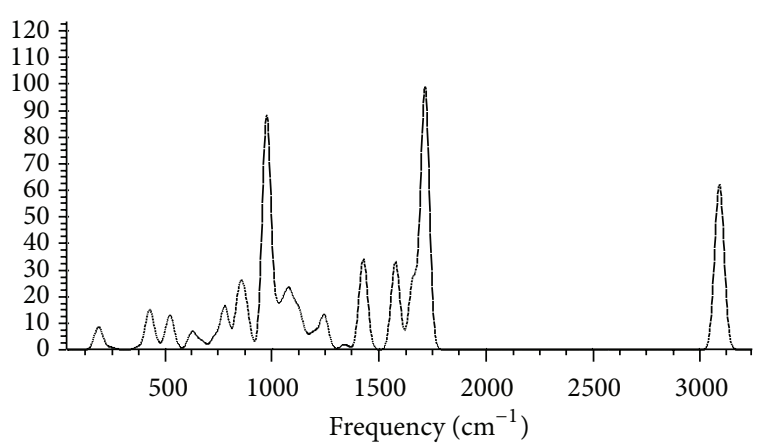

(a)

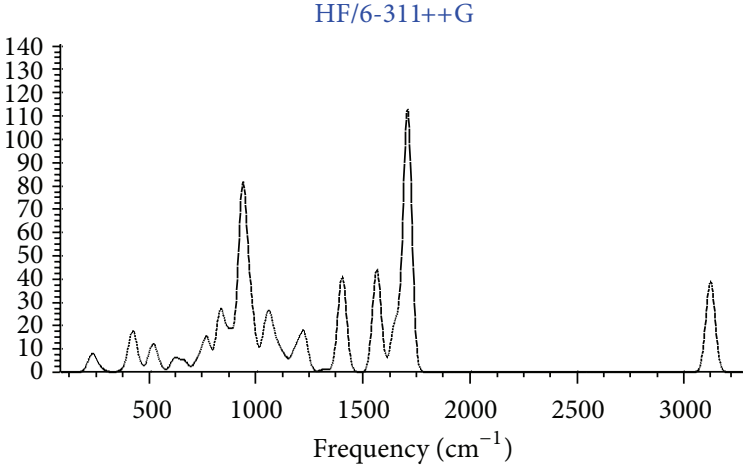

(b)

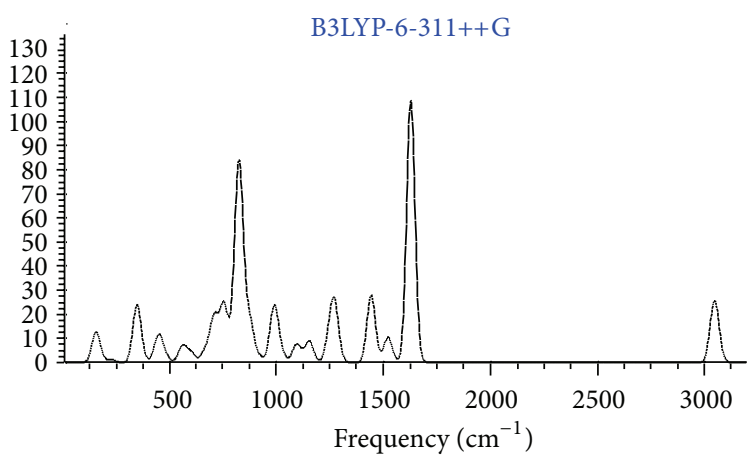

(c)

FIGURE 4: Theoretical FT-IR spectrum of benzothiazole.

to be higher than B3LYP at 6-311+G $(d, p)$ level whereas in the case of Raman activities the trend is reverse.

3.3. NBO Analysis. The natural bond orbital analysis provides an efficient method for studying intra- and intermolecular bonding and interaction among bonds and also provides a convenient basis for investigating charge transfer or conjugative interaction in molecular systems. Some electron donor orbital, acceptor orbital, and the interacting stabilization energy resulting from the second-order microdisturbance theory are reported [41]. NBO analysis has been performed on the title molecule in order to elucidate the intermolecular, rehybridization, and delocalization of electron density within the molecule, which are presented in Tables 4 and 5. A large diversity of energy values was found. The stronger donor character is shown by the p-type lone pair of the nitrogen atoms. The most important interaction $\left(n-\sigma^{*}\right)$ energies, related to the resonance in the molecules, are electron donation from the LP(1)S atoms of the electron donating groups to the antibonding acceptor $\pi^{*}(\mathrm{C}-\mathrm{N})$ of the phenyl 


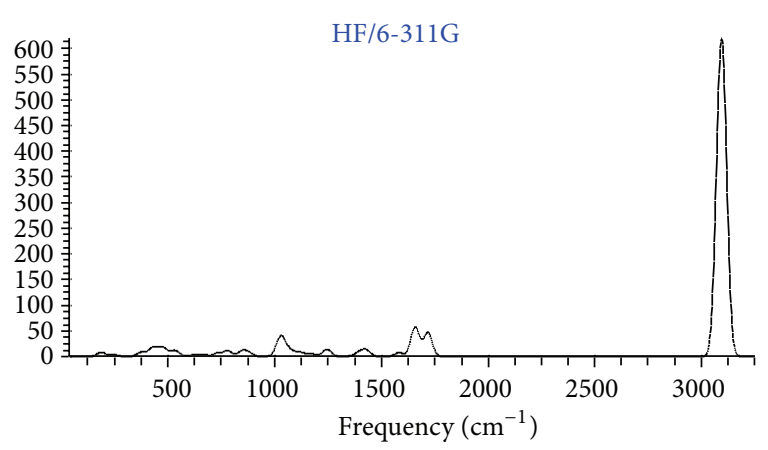

(a)

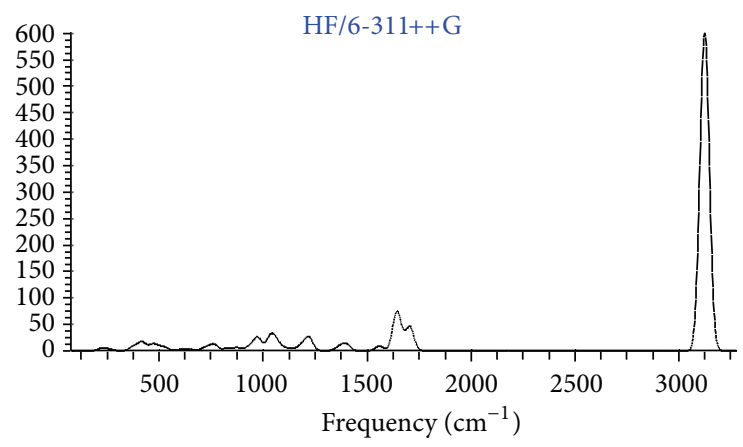

(b)

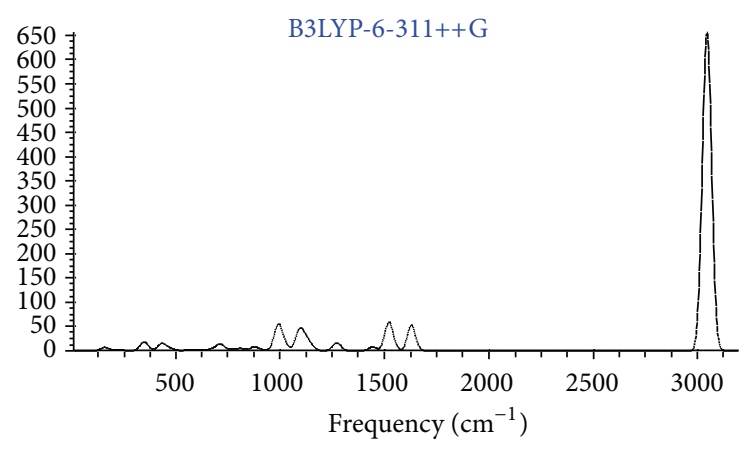

(c)

FIgURE 5: Theoretical FT-Raman spectrum of benzothiazole.

ring $\mathrm{LP}(1) \mathrm{S} 1 \rightarrow \sigma^{*}(\mathrm{C} 2-\mathrm{N} 3)=1.50 \mathrm{~kJ} \mathrm{~mol}^{-1}$. This larger energy shows the hyperconjugation between the electron do nating groups and the phenyl ring. $\mathrm{NBO}$ analysis has been performed on the BT at the HF/6-11++G (d, p) and DFT level in order to elucidate the intramolecular, rehybridization, and delocalization of electron density within the molecule. The intramolecular interactions are formed by the orbital overlap between bonding $(\mathrm{C}-\mathrm{C})$ and $(\mathrm{C}-\mathrm{C})$ antibond orbital which results in intramolecular charge transfer (IC T) causing stabilization of the system. These interactions are observed as increase in electron density (ED) in C-C antibonding orbital that weakens the respective bonds. The strong intramolecular conjugative interaction of the $\sigma$ electron of (S1-C2) distribute to $\sigma^{*}$ (S1-C2), C4-C5, C4-C6, and C5-C9 of the ring. On the other hand, the $\pi(\mathrm{C} 2-\mathrm{N} 3)$ in the ring conjugate to the antibonding orbital of $\pi^{*}$ (C4-C6) leads to strong delocalization of $18.48 \mathrm{~kJ} / \mathrm{mol}$. The $\pi(\mathrm{C} 4-\mathrm{C} 6)$ bond is interacting with $\pi^{*}$ $(\mathrm{C} 2-\mathrm{N} 3)$ with the energy $12.45 \mathrm{kcal} / \mathrm{mol}$ for BT. The $\sigma(\mathrm{C} 4-$ C5) bond is interacting with $\sigma^{*}$ (C2-H10), $\sigma^{*}$ (C4-C6), $\sigma^{*}$ (C5-C9), $\sigma^{*}(\mathrm{C} 6-\mathrm{H} 11), \sigma^{*}$ (C9-H14) with the energies 0.68 , $5.03,5.14,2.13,2.37 \mathrm{kcal} / \mathrm{mol}$ for BT. The energy vlaues of MOs of benzene ring $\sigma$ (C4-C6, C6-C7, C7-C8, C8-C9), $\pi$ (C9C5) are respectively $4.16,4.51,2.83,5.69,3.79 \mathrm{kcal} / \mathrm{mol}$ for BT.

3.4. Frontier Molecular Orbitals (FMOs). The highest occupied molecular orbitals (HOMOs) and the lowest-lying unoccupied molecular orbitals (LUMOs) are called frontier molecular orbital's (FMOs). The FMOs play an important role in the optical and electric properties, as well as in quantum chemistry and UV-vis spectra [37]. The HOMO represents the ability to donate an electron; LUMO as an electron acceptor represents the ability to obtain an electron. The energy gap between HOMO and LUMO determines the kinetic stability, chemical reactivity, and optical polarizability and chemical hardness-softness of a molecule $[42,43]$.

In order to evaluate the energetic behavior of the title compound, we carried out calculations in vacuo and in organic solvent (ethanol). The energies of important molecular orbitals of BT, the highest occupied MOs (HOMO) the lowest unoccupied MOs (LUMO) were calculated using $\mathrm{HF} / 6-311++\mathrm{G}(\mathrm{d}, \mathrm{p})$. The energy values of HOMO and LUMO are $-0.2449,-0.05227$, respectively. The $3 \mathrm{D}$ plots of the HOMO, LUMO orbitals computed for BT molecule are illustrated in Figure 6. The positive phase is red and the negative one is green. It is evident from the figure that while the HOMO is localized on almost the whole molecule, LUMO is localized on the thiazole ring. Both the HOMOs and the LUMOs are mostly $\pi$ antibonding type orbitals. The calculated energy value of HOMO is $-6.4099 \mathrm{eV}$ and LUMO is $-2.038 \mathrm{eV}$, respectively. The energy separation between the HOMO and the LUMO is $-4.4061 \mathrm{eV}$, respectively. The energy gap of HOMO-LUMO explains the eventual charge transfer interaction within the molecule, which influences the biological activity. The wavelength of maximum absorption, excitation energies $E(\mathrm{eV})$, and oscillator strengths $(f)$ of benzothiazole are calculated and given in Table 6. Figure 7 contains theoretically deduced UV-vis spectrum of BT in ethanol employing the TD-HF/6-311++G (d, p) method. 
TABLE 4: Second-order perturbation theory analysis of Fock matrix in NBO basis for benzothiazole.

\begin{tabular}{|c|c|c|c|c|c|c|c|c|}
\hline Donor $(i)$ & Type & $\mathrm{ED} / \mathrm{e}$ & Acceptor $(j)$ & Type & $\mathrm{ED} / \mathrm{e}$ & $E(2)$ & $E(j)-E(i)^{\text {b }}$ (a. u. $)$ & $F(i, j)^{\mathrm{c}}$ (a. u.) \\
\hline \multirow[t]{5}{*}{ S1-C2 } & $\sigma$ & 1.97599 & S1-C2 & $\sigma^{*}$ & 0.07093 & 0.70 & 0.92 & 0.023 \\
\hline & & & C4-C5 & $\sigma^{*}$ & 0.03211 & 0.78 & 1.46 & 0.030 \\
\hline & & & C4-C6 & $\sigma^{*}$ & 0.02151 & 1.04 & 1.50 & 0.035 \\
\hline & & & C5-C9 & $\sigma^{*}$ & 0.02268 & 5.97 & 1.49 & 0.084 \\
\hline & & & C5-C9 & $\pi^{*}$ & 0.35040 & 3.63 & 0.84 & 0.054 \\
\hline \multirow[t]{4}{*}{ S1-C5 } & $\sigma$ & 1.97203 & $\mathrm{C} 2-\mathrm{N} 3$ & $\pi^{*}$ & 0.07212 & 1.82 & 0.96 & 0.038 \\
\hline & & & $\mathrm{C} 2-\mathrm{H} 10$ & $\sigma^{*}$ & 0.02234 & 2.59 & 1.46 & 0.055 \\
\hline & & & C5-C9 & $\sigma^{*}$ & 0.02268 & 0.72 & 1.54 & 0.030 \\
\hline & & & $\mathrm{C} 8-\mathrm{C} 9$ & $\sigma^{*}$ & 0.01365 & 2.97 & 1.55 & 0.061 \\
\hline \multirow[t]{4}{*}{$\mathrm{C} 2-\mathrm{N} 3$} & $\sigma$ & 1.99261 & $\mathrm{C} 2-\mathrm{H} 10$ & $\sigma^{*}$ & 0.02234 & 1.26 & 1.90 & 0.044 \\
\hline & & & N3-C4 & $\sigma^{*}$ & 0.02497 & 0.94 & 1.77 & 0.037 \\
\hline & & & C4-C6 & $\sigma^{*}$ & 0.02151 & 3.53 & 1.99 & 0.075 \\
\hline & & & C4-C6 & $\pi^{*}$ & 0.34604 & 0.80 & 1.34 & 0.032 \\
\hline \multirow[t]{2}{*}{$\mathrm{C} 2-\mathrm{N} 3$} & $\pi$ & 1.95466 & N3-C4 & $\sigma^{*}$ & 0.02497 & 1.36 & 1.07 & 0.034 \\
\hline & & & C4-C6 & $\pi^{*}$ & 0.34604 & 18.48 & 0.64 & 0.106 \\
\hline \multirow[t]{2}{*}{ C2-H10 } & $\sigma$ & 1.98286 & $\mathrm{C} 2-\mathrm{N} 3$ & $\sigma^{*}$ & 0.01757 & 1.83 & 1.60 & 0.048 \\
\hline & & & N3-C4 & $\sigma^{*}$ & 0.02497 & 8.01 & 1.33 & 0.092 \\
\hline \multirow[t]{6}{*}{$\mathrm{N} 3-\mathrm{C} 4$} & $\sigma$ & 1.97560 & S1-C2 & $\sigma^{*}$ & 0.07093 & 1.12 & 1.15 & 0.032 \\
\hline & & & $\mathrm{C} 2-\mathrm{H} 10$ & $\sigma^{*}$ & 0.02234 & 7.02 & 1.64 & 0.096 \\
\hline & & & C4-C5 & $\sigma^{*}$ & 0.03211 & 0.54 & 1.69 & 0.027 \\
\hline & & & C4-C6 & $\sigma^{*}$ & 0.02151 & 1.23 & 1.73 & 0.041 \\
\hline & & & C5-C9 & $\sigma^{*}$ & 0.02268 & 2.69 & 1.73 & 0.061 \\
\hline & & & C6-C7 & $\sigma^{*}$ & 0.01185 & 1.80 & 1.74 & 0.050 \\
\hline \multirow[t]{5}{*}{$\mathrm{C} 4-\mathrm{C} 5$} & $\sigma$ & 1.97874 & $\mathrm{C} 2-\mathrm{H} 10$ & $\sigma^{*}$ & 0.02234 & 0.68 & 1.65 & 0.030 \\
\hline & & & C4-C6 & $\sigma^{*}$ & 0.02151 & 5.03 & 1.74 & 0.084 \\
\hline & & & C5-C9 & $\sigma^{*}$ & 0.02268 & 5.14 & 1.74 & 0.084 \\
\hline & & & C6-H11 & $\sigma^{*}$ & 0.00915 & 2.13 & 1.66 & 0.053 \\
\hline & & & C9-H14 & $\sigma^{*}$ & 0.01004 & 2.37 & 1.66 & 0.056 \\
\hline \multirow[t]{8}{*}{ C4-C6 } & $\sigma$ & 1.97510 & S1-C5 & $\sigma^{*}$ & 0.01756 & 4.16 & 1.22 & 0.064 \\
\hline & & & $\mathrm{C} 2-\mathrm{N} 3$ & $\sigma^{*}$ & 0.01757 & 1.50 & 1.76 & 0.046 \\
\hline & & & $\mathrm{C} 2-\mathrm{N} 3$ & $\pi^{*}$ & 0.07212 & 0.53 & 1.12 & 0.022 \\
\hline & & & N3-C4 & $\sigma^{*}$ & 0.02497 & 1.34 & 1.50 & 0.040 \\
\hline & & & $\mathrm{C} 4-\mathrm{C} 5$ & $\sigma^{*}$ & 0.03211 & 5.54 & 1.68 & 0.086 \\
\hline & & & C6-C7 & $\sigma^{*}$ & 0.01185 & 2.72 & 1.72 & 0.061 \\
\hline & & & C6-H11 & $\sigma^{*}$ & 0.00915 & 1.69 & 1.64 & 0.047 \\
\hline & & & C7-H12 & $\sigma^{*}$ & 0.00908 & 2.25 & 1.64 & 0.054 \\
\hline \multirow[t]{4}{*}{ C4-C6 } & $\pi$ & 1.66368 & $\mathrm{C} 2-\mathrm{N} 3$ & $\pi^{*}$ & 0.07212 & 12.45 & 0.52 & 0.077 \\
\hline & & & N3-C4 & $\sigma^{*}$ & 0.02497 & 0.94 & 0.90 & 0.028 \\
\hline & & & C5-C9 & $\pi^{*}$ & 0.35040 & 39.19 & 0.46 & 0.120 \\
\hline & & & C7-C8 & $\pi^{*}$ & 0.32093 & 39.20 & 0.47 & 0.122 \\
\hline \multirow[t]{5}{*}{ C5-C9 } & $\sigma$ & 1.98148 & N3-C4 & $\sigma^{*}$ & 0.02497 & 3.01 & 1.52 & 0.060 \\
\hline & & & $\mathrm{C} 4-\mathrm{C} 5$ & $\sigma^{*}$ & 0.03211 & 5.38 & 1.70 & 0.086 \\
\hline & & & $\mathrm{C} 8-\mathrm{C} 9$ & $\sigma^{*}$ & 0.01365 & 3.05 & 1.74 & 0.065 \\
\hline & & & $\mathrm{C} 8-\mathrm{H} 13$ & $\sigma^{*}$ & 0.00886 & 2.08 & 1.65 & 0.052 \\
\hline & & & C9-H14 & $\sigma^{*}$ & 0.01004 & 1.87 & 1.65 & 0.050 \\
\hline \multirow[t]{4}{*}{$\mathrm{C} 5-\mathrm{C} 9$} & $\pi$ & 1.70971 & $\mathrm{C} 2-\mathrm{N} 3$ & $\pi^{*}$ & 0.07212 & 1.23 & 0.54 & 0.024 \\
\hline & & & N3-C4 & $\sigma^{*}$ & 0.02497 & 0.92 & 0.92 & 0.028 \\
\hline & & & C4-C6 & $\pi^{*}$ & 0.34604 & 36.07 & 0.48 & 0.120 \\
\hline & & & $\mathrm{C} 7-\mathrm{C} 8$ & $\pi^{*}$ & 0.32093 & 35.76 & 0.49 & 0.120 \\
\hline
\end{tabular}


TABLE 4: Continued.

\begin{tabular}{|c|c|c|c|c|c|c|c|c|}
\hline Donor $(i)$ & Type & $\mathrm{ED} / \mathrm{e}$ & Acceptor $(j)$ & Type & $\mathrm{ED} / \mathrm{e}$ & $E(2)$ & $E(j)-E(i)^{\text {b }}$ (a. u. $)$ & $F(i, j)^{\mathrm{c}}$ (a. u.) \\
\hline \multirow[t]{6}{*}{ C6-C7 } & $\sigma$ & 1.98054 & N3-C4 & $\sigma^{*}$ & 0.02497 & 4.51 & 1.49 & 0.07 \\
\hline & & & C4-C6 & $\sigma^{*}$ & 0.02151 & 3.29 & 1.71 & 0.067 \\
\hline & & & C6-H11 & $\sigma^{*}$ & 0.00915 & 1.53 & 1.63 & 0.045 \\
\hline & & & C7-C8 & $\sigma^{*}$ & 0.01359 & 2.85 & 1.71 & 0.062 \\
\hline & & & C7-H12 & $\sigma^{*}$ & 0.00908 & 1.44 & 1.63 & 0.043 \\
\hline & & & C8-H13 & $\sigma^{*}$ & 0.00886 & 2.56 & 1.62 & 0.058 \\
\hline \multirow[t]{5}{*}{ C6-H11 } & $\sigma$ & 1.98222 & N3-C4 & $\sigma^{*}$ & 0.02497 & 0.55 & 1.28 & 0.024 \\
\hline & & & $\mathrm{C} 4-\mathrm{C} 5$ & $\sigma^{*}$ & 0.03211 & 5.08 & 1.46 & 0.077 \\
\hline & & & C4-C6 & $\sigma^{*}$ & 0.02151 & 1.42 & 1.50 & 0.041 \\
\hline & & & C6-C7 & $\sigma^{*}$ & 0.01185 & 1.33 & 1.50 & 0.040 \\
\hline & & & C7-C8 & $\sigma^{*}$ & 0.01359 & 4.20 & 1.50 & 0.071 \\
\hline \multirow[t]{6}{*}{$\mathrm{C} 7-\mathrm{C} 8$} & $\sigma$ & 1.98272 & C6-C7 & $\sigma^{*}$ & 0.01185 & 2.83 & 1.71 & 0.062 \\
\hline & & & C6-H11 & $\sigma^{*}$ & 0.00915 & 2.48 & 1.63 & 0.057 \\
\hline & & & C7-H12 & $\sigma^{*}$ & 0.00908 & 1.55 & 1.63 & 0.045 \\
\hline & & & C8-C9 & $\sigma^{*}$ & 0.01365 & 2.90 & 1.71 & 0.063 \\
\hline & & & C8-H13 & $\sigma^{*}$ & 0.00886 & 1.56 & 1.62 & 0.045 \\
\hline & & & C9-H14 & $\sigma^{*}$ & 0.01004 & 2.59 & 1.62 & 0.058 \\
\hline \multirow[t]{2}{*}{$\mathrm{C} 7-\mathrm{C} 8$} & $\pi$ & 1.67584 & C4-C6 & $\pi^{*}$ & 0.34604 & 42.89 & 0.46 & 0.126 \\
\hline & & & C5-C9 & $\pi^{*}$ & 0.35040 & 42.80 & 0.45 & 0.125 \\
\hline \multirow[t]{4}{*}{ C7-H12 } & $\sigma$ & 1.98449 & C4-C6 & $\sigma^{*}$ & 0.02151 & 4.40 & 1.50 & 0.073 \\
\hline & & & C6-C7 & $\sigma^{*}$ & 0.01185 & 1.28 & 1.50 & 0.039 \\
\hline & & & C7-C8 & $\sigma^{*}$ & 0.01359 & 1.29 & 1.50 & 0.039 \\
\hline & & & $\mathrm{C} 8-\mathrm{C} 9$ & $\sigma^{*}$ & 0.01365 & 4.20 & 1.50 & 0.071 \\
\hline \multirow[t]{6}{*}{$\mathrm{C} 8-\mathrm{C} 9$} & $\sigma$ & 1.97778 & S1-C5 & $\sigma^{*}$ & 0.01756 & 5.69 & 1.21 & 0.074 \\
\hline & & & C5-C9 & $\sigma^{*}$ & 0.02268 & 3.97 & 1.70 & 0.073 \\
\hline & & & C7-C8 & $\sigma^{*}$ & 0.01359 & 2.83 & 1.71 & 0.062 \\
\hline & & & C7-H12 & $\sigma^{*}$ & 0.00908 & 2.51 & 1.63 & 0.057 \\
\hline & & & C8-H13 & $\sigma^{*}$ & 0.00886 & 1.43 & 1.63 & 0.043 \\
\hline & & & C9-H14 & $\sigma^{*}$ & 0.01004 & 1.53 & 1.62 & 0.045 \\
\hline \multirow[t]{4}{*}{ C8-H13 } & $\sigma$ & 1.98412 & C5-C9 & $\sigma^{*}$ & 0.02268 & 4.70 & 1.49 & 0.075 \\
\hline & & & C6-C7 & $\sigma^{*}$ & 0.01185 & 4.16 & 1.50 & 0.071 \\
\hline & & & C7-C8 & $\sigma^{*}$ & 0.01359 & 1.29 & 1.50 & 0.039 \\
\hline & & & $\mathrm{C} 8-\mathrm{C} 9$ & $\sigma^{*}$ & 0.01365 & 1.26 & 1.50 & 0.039 \\
\hline \multirow[t]{4}{*}{ C9-H14 } & $\sigma$ & 1.98424 & $\mathrm{C} 4-\mathrm{C} 5$ & $\sigma^{*}$ & 0.03211 & 4.44 & 1.46 & 0.072 \\
\hline & & & C5-C9 & $\sigma^{*}$ & 0.02268 & 1.54 & 1.49 & 0.043 \\
\hline & & & C7-C8 & $\sigma^{*}$ & 0.01359 & 4.07 & 1.50 & 0.070 \\
\hline & & & $\mathrm{C} 8-\mathrm{C} 9$ & $\sigma^{*}$ & 0.01365 & 1.33 & 1.50 & 0.040 \\
\hline \multirow[t]{2}{*}{ C4-C6 } & $\pi^{*}$ & 0.34604 & $\mathrm{C} 2-\mathrm{N} 3$ & $\pi^{*}$ & 0.07212 & 18.62 & 0.05 & 0.062 \\
\hline & & & N3-C4 & $\sigma^{*}$ & 0.02497 & 2.79 & 0.43 & 0.072 \\
\hline \multirow[t]{2}{*}{ C5-C9 } & $\pi^{*}$ & 0.35040 & $\mathrm{C} 2-\mathrm{N} 3$ & $\pi^{*}$ & 0.07212 & 3.79 & 0.06 & 0.030 \\
\hline & & & C7-C8 & $\pi^{*}$ & 0.32093 & 371.30 & 0.02 & 0.122 \\
\hline
\end{tabular}

${ }^{\mathrm{a}} E(2)$ means energy of hyperconjugative interaction (stabilization energy).

${ }^{\mathrm{b}}$ Energy difference between donor and acceptor $i$ and $j \mathrm{NBO}$ orbitals.

${ }^{\mathrm{c}} F(i, j)$ is the Fock matrix element between $i$ and $j$ NBO orbitals.

3.5. Thermodynamic Properties. The values of thermodynamic parameters zero point vibrational energy, thermal energy, specific heat capacity, rotational constants, entropy of $\mathrm{BT}$ at $298.15 \mathrm{~K}$ in ground state are listed in Table 7. The variation in zero point vibrational energies (ZPVEs) seems to be significant. The ZPVE is much lower by the DFT/B3LYP method than by the HF method. The high value of ZPVE of
BT is $65.51 \mathrm{kcl} / \mathrm{mol}$ obtained at $\mathrm{HF} / 6-311++\mathrm{G}(\mathrm{d}, \mathrm{p})$ whereas the smallest values is $61.63 \mathrm{kcal} / \mathrm{mol}$ obtained at B3LYP/6$311++\mathrm{G}(\mathrm{d}, \mathrm{p})$. Dipole moment reflects the molecular charge distribution and is given as a vector in three dimensions. Therefore, it can be used as descriptor to depict the charge movement across the molecule. Direction of the dipole moment vector in a molecule depends on the centers of 
TABLE 5: Second-order perturbation energies $E(2)$ (donor $\rightarrow$ acceptor) for benzothiazole.

\begin{tabular}{|c|c|c|c|c|}
\hline Donor $(i)$ & Acceptor $(j)$ & $E(2)\left(\mathrm{kJ} \mathrm{mol}^{-1}\right)^{\mathrm{a}}$ & $E(j)-E(i)^{\text {b }}$ (a. u. $)$ & $F(i, j)^{\mathrm{c}}$ (a. u.) \\
\hline \multicolumn{5}{|l|}{ Within unit 1} \\
\hline LP (1) S1 & $\sigma^{*} \mathrm{C} 2-\mathrm{N} 3$ & 1.50 & 1.70 & 0.045 \\
\hline LP (1) S1 & $\pi^{*} \mathrm{C} 2-\mathrm{N} 3$ & 1.38 & 1.05 & 0.035 \\
\hline LP (1) S1 & $\sigma^{*} \mathrm{C} 4-\mathrm{C} 5$ & 1.77 & 1.61 & 0.048 \\
\hline LP (1) S1 & $\sigma^{*} \mathrm{C} 5-\mathrm{C} 9$ & 0.52 & 1.64 & 0.026 \\
\hline $\mathrm{LP}(2) \mathrm{S} 1$ & $\pi^{*} \mathrm{C} 2-\mathrm{N} 3$ & 8.98 & 0.59 & 0.065 \\
\hline LP (2) S1 & $\sigma^{*} \mathrm{C} 2-\mathrm{H} 10$ & 1.41 & 1.09 & 0.036 \\
\hline $\mathrm{LP}(2) \mathrm{S} 1$ & $\sigma^{*} \mathrm{C} 4-\mathrm{C} 5$ & 1.21 & 1.14 & 0.034 \\
\hline $\mathrm{LP}(2) \mathrm{S} 1$ & $\sigma^{*} \mathrm{C} 5-\mathrm{C} 9$ & 1.98 & 1.18 & 0.044 \\
\hline LP (1) N3 & $\sigma^{*} \mathrm{C} 2-\mathrm{N} 6$ & 2.64 & 1.17 & 0.050 \\
\hline LP (1) N3 & $\sigma^{*} \mathrm{C} 4-\mathrm{C} 5$ & 9.23 & 1.38 & 0.102 \\
\hline LP (1) N3 & $\sigma^{*} \mathrm{C} 4-\mathrm{H} 7$ & 3.47 & 1.25 & 0.060 \\
\hline LP (1) N3 & $\sigma^{*} \mathrm{~S} 1-\mathrm{C} 2$ & 27.32 & 0.77 & 0.130 \\
\hline LP (1) N3 & $\sigma^{*} \mathrm{C} 4-\mathrm{C} 6$ & 0.85 & 1.35 & 0.031 \\
\hline LP (1) N3 & $\sigma^{*} \mathrm{C} 4-\mathrm{C} 6$ & 1.17 & 0.70 & 0.027 \\
\hline
\end{tabular}

${ }^{a} E(2)$ means energy of hyper conjugative interaction (stabilization energy).

${ }^{\mathrm{b}}$ Energy difference between donor and acceptor $i$ and $j \mathrm{NBO}$ orbitals.

${ }^{\mathrm{c}} F(i, j)$ is the Fock matrix element between $i$ and $j$ NBO orbitals.

TABLE 6: Calculated absorption wavelength $(\mathrm{nm})$, excitation energies $E(\mathrm{eV})$, and oscillator strengths $(f)$ of benzothiazole.

\begin{tabular}{lcccc}
\hline & $\begin{array}{c}\text { TD-HF/6-311++G }(\mathrm{d}, \mathrm{p}) \\
\text { Ethanol } \\
\lambda(\mathrm{mn})\end{array}$ & $E(\mathrm{eV})$ & $\lambda(\mathrm{mn})$ & \multicolumn{2}{c}{$\begin{array}{c}\text { TD-HF/6-311++G }(\mathrm{d}, \mathrm{p}) \\
\text { Gas phase } \\
(f)\end{array}$} & $4.0241 \mathrm{eV}$ & 308.66 & 0.0265 \\
\hline 308.1 & 0.0333 & $4.6784 \mathrm{eV}$ & 267.95 & 0.001 \\
265.01 & 0.0013 & $4.9051 \mathrm{eV}$ & 254.78 & 0.0018 \\
252.77 & 0.0025 & & $4.0169 \mathrm{eV}$ \\
\hline
\end{tabular}

TABLE 7: The calculated thermodynamical parameter of benzothiazole.

\begin{tabular}{|c|c|c|c|c|}
\hline Basis Set & $\mathrm{HF} / 6-31 \mathrm{G}$ & $\mathrm{HF} / 6-311 \mathrm{G}$ & $\mathrm{HF} / 6-311++\mathrm{G}(\mathrm{d}, \mathrm{p})$ & B3LYP/6-311++G (d, p) \\
\hline Zero point energy (Kcal/Mol) & 66.93709 & 66.140 & 65.51671 & 61.63 \\
\hline Rotational constant & 2.93435 & 2.93435 & 2.93435 & 2.93435 \\
\hline Rotational temperature & 0.14083 & 0.14083 & 0.14083 & 0.14083 \\
\hline \multicolumn{5}{|l|}{ Energy $(E)$} \\
\hline Translational & 0.889 & 0.889 & 0.889 & 0.889 \\
\hline Rotational & 0.889 & 0.889 & 0.889 & 0.889 \\
\hline Vibrational & 68.158 & 68.168 & 67.551 & 64.058 \\
\hline Total & 70.689 & 69.988 & 69.329 & 65.836 \\
\hline \multicolumn{5}{|l|}{ Specific heat $\left(C_{v}\right)$} \\
\hline Translational & 2.981 & 2.981 & 2.981 & 2.981 \\
\hline Rotational & 2.981 & 2.981 & 2.981 & 2.981 \\
\hline Vibrational & 17.963 & 17.973 & 18.512 & 15.283 \\
\hline Total & 23.627 & 23.935 & 20.895 & 21.245 \\
\hline \multicolumn{5}{|l|}{ Entropy $(S)$} \\
\hline Translational & 40.613 & 40.613 & 40.613 & 40.613 \\
\hline Rotational & 28.903 & 28.903 & 28.903 & 28.903 \\
\hline Vibrational & 10.154 & 10.167 & 10.040 & 12.445 \\
\hline Total & 79.436 & 79.683 & 79.556 & 81.961 \\
\hline Dipole moment & 2.0974 & 2.0507 & 1.6331 & 1.4713 \\
\hline
\end{tabular}


TABLE 8: Mulliken atomic charges of benzothiazole.

\begin{tabular}{lcccc}
\hline Atoms & HF/6-31G & HF/6-311G & HF/6-311++G $(\mathrm{d}, \mathrm{p})$ & B3LYP/6-311++G $(\mathrm{d}, \mathrm{p})$ \\
\hline S1 & 0.494254 & 0.283343 & -0.428958 & -0.305656 \\
C2 & -0.223616 & -0.09723 & -0.1285 & -0.174194 \\
N3 & -0.43924 & -0.377701 & 0.038389 & 0.055788 \\
C4 & 0.177233 & 0.264898 & -0.932014 & -0.938592 \\
C5 & -0.403325 & -0.453121 & 1.000645 & 0.984567 \\
C6 & -0.120432 & -0.167237 & -0.43895 & -0.437759 \\
C7 & -0.221659 & -0.165775 & -0.377287 & -0.307896 \\
C8 & -0.184873 & -0.144593 & -0.246147 & -0.081338 \\
C9 & -0.19687 & 0.218665 & 0.313292 & 0.218011 \\
H10 & 0.242781 & 0.192916 & 0.275732 & 0.255925 \\
H11 & 0.235255 & 0.244504 & 0.193902 \\
H12 & 0.209181 & 0.176608 & 0.217394 & 0.172514 \\
H13 & 0.207899 & 0.178898 & 0.216713 & 0.174776 \\
H14 & 0.223413 & 0.18351 & 0.245187 & 0.189952 \\
\hline
\end{tabular}
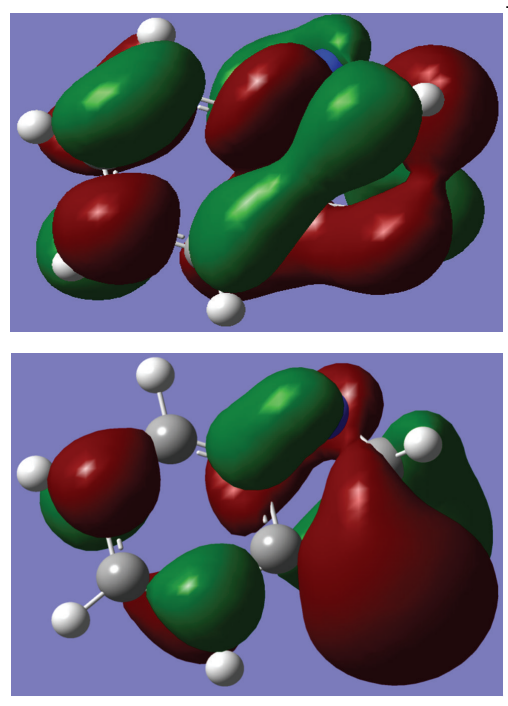

$\Delta E=-4.4061$

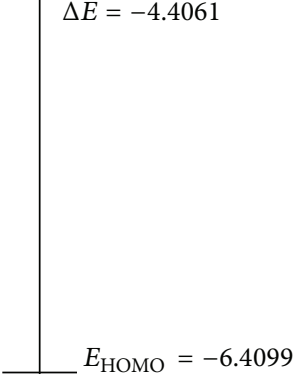

Figure 6: The molecular orbitals and energies for the HOMO and LUMO of the title compound.

positive and negative charges. Dipole moments are strictly determined for neutral molecules. For charged systems, its value depends on the choice of origin and molecular orientation. As a result of HF and DFT (B3LYP) calculations, the highest dipole moment was observed for B3LYP/6$311 \mathrm{G}++(\mathrm{d}, \mathrm{p})$ whereas the smallest one was observed for $\mathrm{HF} / 6-311++\mathrm{G}(\mathrm{d}, \mathrm{p})$ in each molecule.

On the basis of vibrational analysis, the statically thermodynamic functions: heat capacity (C), entropy (S), and enthalpy changes $(\mathrm{DH})$ for the title molecule were obtained from the theoretical harmonic frequencies and listed in Table 7. From the data in this table, it can be observed that these thermodynamic functions are increasing with temperature ranging from 100 to $600 \mathrm{~K}$ due to the fact that the molecular vibrational intensities increase with temperature [44].

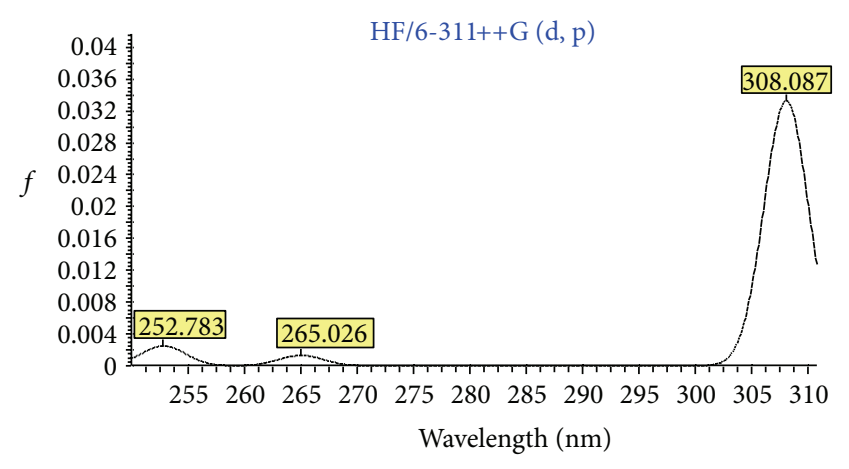

FIGURE 7: Theoretical UV-vis spectrum in ethanol for the title molecule calculated with the TD-HF/6-311++G (d, p) method.

3.6. Mulliken Atomic Charges. Mulliken atomic charge calculation is an important tool in the application of quantum chemical calculation to molecular system because atomic charges influence dipole moment, molecular polarizability, electronic structure, and other physical properties of molecular systems. The calculated Mulliken charge values are listed in Table 8. The atomic charge depends on basis set presumably occur due to polarization. For example, the charge of $\mathrm{N}$ (3) atom is -0.43924 for $\mathrm{HF} / 6-31 \mathrm{G},-0.377701$ for $\mathrm{HF} / 6-311 \mathrm{G}, 0.038389$ for $\mathrm{HF} / 6-311++\mathrm{G}(\mathrm{d}, \mathrm{p})$, and 0.055788 for B3LYP/6-311++G (d, p). The charge distribution of sulfur group is increasing trend in HF and B3LYP methods. The charge of $\mathrm{H} 10, \mathrm{H} 11, \mathrm{H} 12, \mathrm{H} 13$, and $\mathrm{H} 14$ is positive in both $\mathrm{HF}$ and DFT diffuse functions. Considering all methods and basis sets used in the atomic charge calculation, the carbon atoms exhibit a substatantial negative charge, which are donor atoms. Hydrogen atom exhibits a positive charge, which is an acceptor atom. The Mulliken charge distribution of BT is increasing trend in B3LYP as compared to HF methods. A comparison of Mullikan's Atomic charge obtained by the two theoretical (HF and DFT) approaches is illustrated in Figure 8. It may be seen that the two methods give comparable atomic charges. 


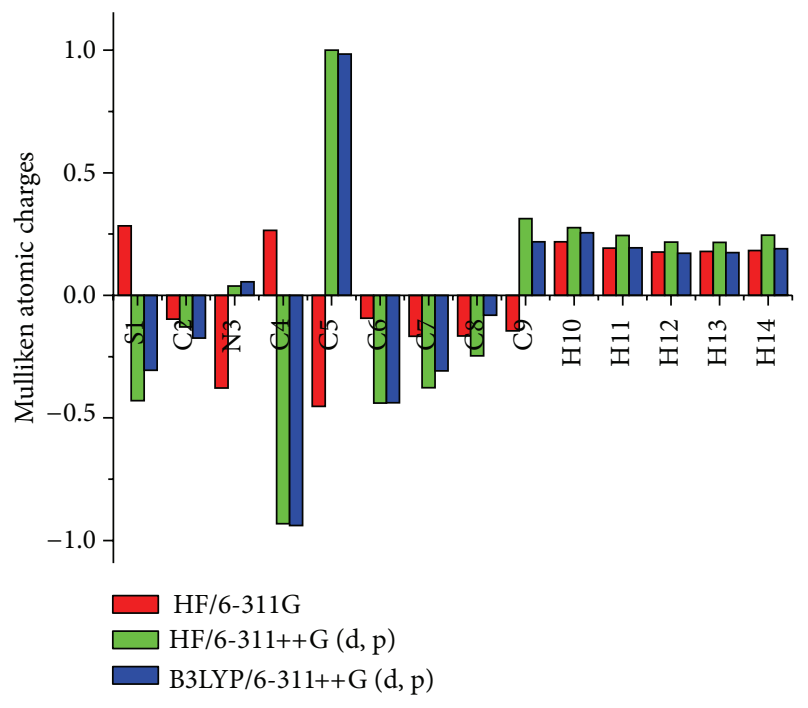

FIGURE 8: Mullikan's atomic charges between theoretical (HF and DFT) approaches.

\section{Conclusion}

In the present work, we have performed the experimental and theoretical vibrational analysis of a pharmaceutically important heterocyclic aromatic molecule, benzothiazole for the first time. The optimized molecular geometry, vibrational frequencies, infrared activities, and Raman scattering activities of the molecule in the ground state have been calculated by using ab initio HF and DFT (B3LYP) methods with $6-311++G(d, p)$ basis set. The vibrational frequencies were calculated and scaled values are compared with the recorded FT-IR and FT-Raman spectra of the compound. The observed and the calculated frequencies are found to be in good agreement. Furthermore, the thermodynamic and total dipole moment properties of the compound have been calculated in order to get insight into molecular structure of the compound. These computations are carried out with the main aim that the results will be of assistance in the quest of the experimental and theoretical evidence for the title molecule in biological activity and coordination chemistry.

\section{References}

[1] H. M. Bryson, B. Fulton, and P. Benfield, "Riluzole. A review of its pharmacodynamic and pharmacokinetic properties and therapeutic potential in amyotrophic lateral sclerosis," Drugs, vol. 52, no. 4, pp. 549-563, 1996.

[2] S. Akihama, M. Okhude, and A. Mizno, Chemical Abstracts, vol. 68, p. $10369 \mathrm{v}, 1968$.

[3] F. Russo and M. Santagati, "Synthesis and determination of the antibacterial activity of benzothiazole derivatives of $1,3,4$ thiadiazole and imidazo [2,1 b]1,3,4 thiadiazole," Farmaco, vol. 31, no. 1, pp. 41-48, 1976 (Italian).

[4] K. M. Ghoneim, S. El-Basil, A. N. Osman, M. M. Said, and S. A. Megahed, "Synthesis and antimicrobial investigation of benzothiazole derivatives," Revue Roumaine de Chimie, vol. 36, pp. 1355-1361, 1991.
[5] S. P. Singh and S. Seghal, "Study of fungicidal activities of some benzothiazoles," Indian Journal of Chemistry B, vol. 27, p. 941, 1988.

[6] J. H. Musser, R. E. Brown, B. Love et al., "Synthesis of 2(2,3-dihydro-2-oxo-1,3,4-oxadiazol-5-yl) benzo heterocycles. A novel series of orally active antiallergic agents," Journal of Medicinal Chemistry, vol. 27, pp. 121-125, 1984.

[7] S. R. Pattan, C. Suresh, V. D. Pujar, V. V. K. Reddy, V. P. Rasal, and B. C. Kotti, "Synthesis and antidiabetic activity of 2-amino [5' (4-sulphonylbenzylidine)-2,4-thiazolidinedione]-7-chloro6-fluorobenzothiazole," Indian Journal of Chemistry B, vol. 44, no. 11, pp. 2404-2408, 2005.

[8] M. Yoshida, I. Hayakawa, N. Hyashi et al., "Synthesis and biological evaluation of benzothiazole derivatives as potent antitumor agents," Bioorganic \& Medicinal Chemistry Letters, vol. 15, pp. 3328-3332, 2005.

[9] S. N. Sawhney, R. K. Tomer, O. M. Prakash, I. Prakash, and S. P. Singh, "Benzothiazole derivatives: Part XI-Synthesis and anti-inflammatory activity of some $2-\left(3^{\prime}-5^{\prime}\right.$-dimethyl $-4^{\prime}$ substituted-pyrazole-1'-yl) benzothiazoles," Indian Journal of Chemistry B, vol. 20, pp. 314-316, 1981.

[10] H. D. Brown, Chemical Abstracts, vol. 65, p. 18593, 1966.

[11] C. O. Leong, M. Gaskell, G. A. Martin et al., "Antitumour 2-(4-aminophenyl)benzothiazoles generate DNA adducts in sensitive tumour cells in vitro and in vivo," British Journal of Cancer, vol. 88, pp. 470-477, 2003.

[12] T. D. Bradshaw, M. C. Bibby, J. A. Double et al., "Preclinical evaluation of amino acid prodrugs of novel antitumor 2(4-amino-3-methylphenyl)benzothiazoles," Molecular Cancer Therapeutics, vol. 1, no. 4, pp. 239-246, 2002.

[13] I. Hutchinson, S. A. Jennings, B. R. Vishnuvajjala, A. D. Westwell, and M. F. G. Stevens, "Antitumor benzothiazoles. 16. Synthesis and pharmaceutical properties of antitumor 2-(4aminophenyl)benzothiazole amino acid prodrugs," Journal of Medicinal Chemistry, vol. 45, no. 3, pp. 744-747, 2002.

[14] J. Frisch, G. W. Trucks, H. B. Schlegel et al., Gaussian 09 Program, Revision C. 01, Gaussian, Inc, Wallingford, Conn, USA, 2010.

[15] A. D. Becke, "Density-functional thermochemistry. III. The role of exact exchange," The Journal of Chemical Physics, vol. 98, no. 7, pp. 5648-5652, 1993.

[16] G. Rauhut and P. Pulay, "Transferable scaling factors for density functional derived vibrational force fields," The Journal of Physical Chemistry, vol. 99, no. 10, pp. 3093-3100, 1995.

[17] S. Srinivasan, S. Gunasekaran, U. Ponnambalam, A. Savarianandam, S. Gnanaprakasam, and S. Natarajan, "Spectroscopic and thermodynamic analysis of enolic form of 3-oxo-Lgulofuranolactone," Indian Journal of Pure and Applied Physics, vol. 43, no. 6, pp. 459-462, 2005.

[18] G. Socretes, Infrared Characteristic Group Frequencies, John Wiley \& Sons, New York, NY, USA, 1st edition, 1980.

[19] D. Alfè, G. A. De Wijs, G. Kresse, and M. J. Gillan, "Recent developments in ab initio thermodynamics," International Journal of Quantum Chemistry, vol. 77, no. 5, pp. 871-879, 2000.

[20] H. M. Badawi, W. Forner, and Y. S. Oloriegbe, "Theoretical vibrational spectra and potential scans for trichloromethylsulfonyl isocyanate," Journal of Molecular Structure, vol. 548, no. 1-3, pp. 219-227, 2001.

[21] D. Mahadevan, S. Periandy, and S. Ramalingam, "FT-IR and FTRaman, vibrational assignments, molecular geometry, ab initio (HF) and DFT (B3LYP) calculations for 1,3-dichlorobenzene," Spectrochimica Acta A, vol. 79, no. 5, pp. 962-969, 2011. 
[22] M. Batley, R. Bramley, and K. Robinson, "Photophysics of the lowest triplet state in 2-benzoylpyridine crystals. I. Optical spectra," Proceedings of the Royal Society A, vol. 369, pp. 175-185, 1979.

[23] Y. Wang, S. Saebo, and C. U. Pittman Jr., "The structure of aniline by ab initio studies," Journal of Molecular Structure, vol. 281, no. 2-3, pp. 91-98, 1993.

[24] I. Fleming, Frontier Orbitals and Organic Chemical Reactions, John Wiley \& Sons, London, UK, 1976.

[25] A. M. Asiri, M. Karabacak, M. Kurt, and K. A. Alamry, "Synthesis, molecular conformation, vibrational and electronic transition, isometric chemical shift, polarizability and hyperpolarizability analysis of 3-(4-methoxy-phenyl)-2-(4-nitro-phenyl)acrylonitrile: a combined experimental and theoretical analysis," Spectrochim Acta A, vol. 82, pp. 444-455, 2011.

[26] B. Kosar and C. Albayrak, "Spectroscopic investigations and quantum chemical computational study of (E)-4-methoxy-2[(p-tolylimino)methyl]phenol," Spectrochimica Acta A, vol. 78, no. 1, pp. 160-167, 2011.

[27] A. A. El-Azhary, "A DFT study of the geometries and vibrational spectra of indene and some of its heterocyclic analogues, benzofuran, benzoxazole, bensothiophene, benzothiazole, indole and indazole," Spectrochim Acta A, vol. 55, no. 12, pp. 2437-2446, 1999.

[28] Y. Wang, S. Saebo, and C. U. Pittman Jr, “The structure of aniline by ab initio studies," Journal of Molecular Structure, vol. 281, no. 2-3, pp. 91-98, 1993.

[29] A. Altun, K. Gölcük, and M. Kumru, "Structure and vibrational spectra of p-methylaniline: Hartree-Fock, MP2 and density functional theory studies," Journal of Molecular Structure, vol. 637, pp. 155-169, 2003.

[30] J. Coates, Interpretation of Infrared Spectra, A Practical Approach, John Wiley \& Sons, Chichester, UK, 2000.

[31] X. Li, Z. Tang, and X. Zhang, "Molecular structure, IR spectra of 2-mercaptobenzothiazole and 2-mercaptobenzoxazole by density functional theory and ab initio Hartree-Fock calculations ," Spectrochim Acta A, vol. 74, no. 1, pp. 168-173, 2009.

[32] I. Yalcin, E. Sener, T. Ozden, S. Ozden, and A. Akin, "Synthesis and microbiological activity of 5-methyl-2-[p-substituted phenyl]benzoxazoles," European Journal of Medicinal Chemistry, vol. 25, no. 8, pp. 705-708, 1990.

[33] R. Saxena, L. D. Kandpal, and G. N. Mathur, "Synthesis and characterization of poly(benzobisthiazole)s derived from halogenated phthalic acid and isophthalic acid," Journal of Polymer Science A, vol. 40, no. 22, pp. 3959-3966, 2002.

[34] R. M. Silverstein, G. C. Bassler, and T. C. Morril, Spectrometric Identification of Organic Compounds, John Wiley \& Sons, Singapore, 5th edition, 1991.

[35] K. Nakamoto, Infrared and Raman Spectrum of Inorganic and Coordination Compounds, John Wiley \& Sons, NewYork, NY, USA, 5th edition, 1997.

[36] G. Yang, S. I. Matsuzono, E. Koyama, H. Tokuhisa, and K. Hiratani, "A new synthetic route to benzoxazole polymer via tandem claisen rearrangement," Macromolecules, vol. 34, no. 19, pp. 6545-6547, 2001.

[37] G. Varsanyi, Assignments for Vibrational Spectra of Seven Hundred Benzene Derivatives, vol. 1, Adam Hilger, London, UK, 1974.

[38] G. Socrates, Infrared Raman Characteristic Group FrequenciesTables and Charts, John Wiley \& Sons, New York, NY, USA, 3rd edition, 2001.
[39] V. Krishnakumar and R. J. Xavier, "Normal coordinate analysis of 2-mercapto and 4,6-dihydroxy-2-mercapto pyrimidines," Indian Journal of Pure and Applied Physics, vol. 41, pp. 597-601, 2003.

[40] J. N. Liu, Z. R. Chen, and S. F. Yuan, "Study on the prediction of visible absorption maxima of azobenzene compounds," Journal of Zhejiang University Science B, vol. 6, pp. 584-589, 2005.

[41] R. Zhang, B. Dub, G. Sun, and Y. Sun, "Experimental and theoretical studies on $o$-, $m$ - and $p$-chlorobenzylideneaminoantipyrines," Spectrochimica Acta A, vol. 75, pp. 1115-1124, 2010.

[42] L. J. Bellamy, The Infrared Spectra of Complex Molecules, John Wiley \& Sons, NewYork, NY, USA, 3rd edition, 1975.

[43] E. Koglin, E. G. Witte, and R. J. Meier, “The vibrational spectra of metabolites of methabenzthiazuron: 2-amino-benzothiazole and 2-(methylamino)benzothiazole," Vibrational Spectroscopy, vol. 33, no. 1-2, pp. 49-61, 2003.

[44] C. James, A. A. Raj, R. Reghunathan, I. H. Joe, and V. S. Jayakumar, "Structural conformation and vibrational spectroscopic studies of 2,6-bis ( $p$-N,N-dimethyl benzylidene) cyclohexanone using density functional theory," Journal of Raman Spectroscopy, vol. 37, no. 12, pp. 1381-1392, 2006. 

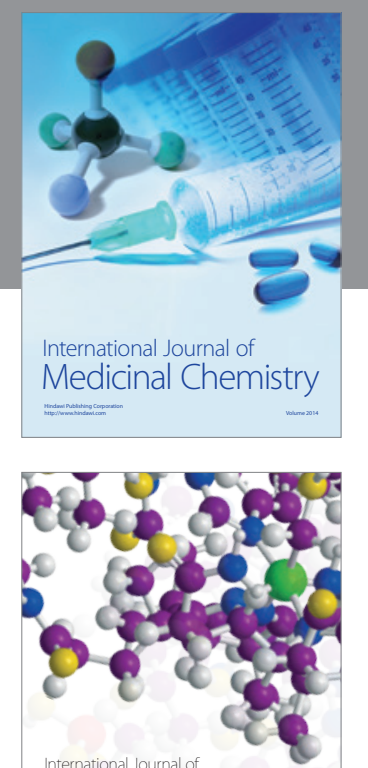

\section{Carbohydrate} Chemistry

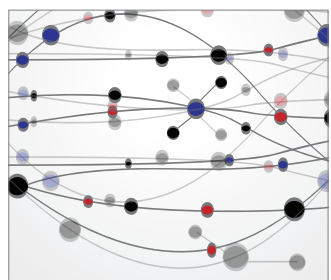

The Scientific World Journal
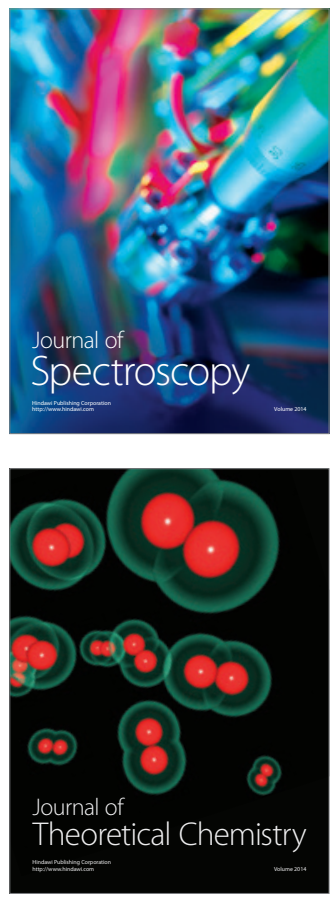
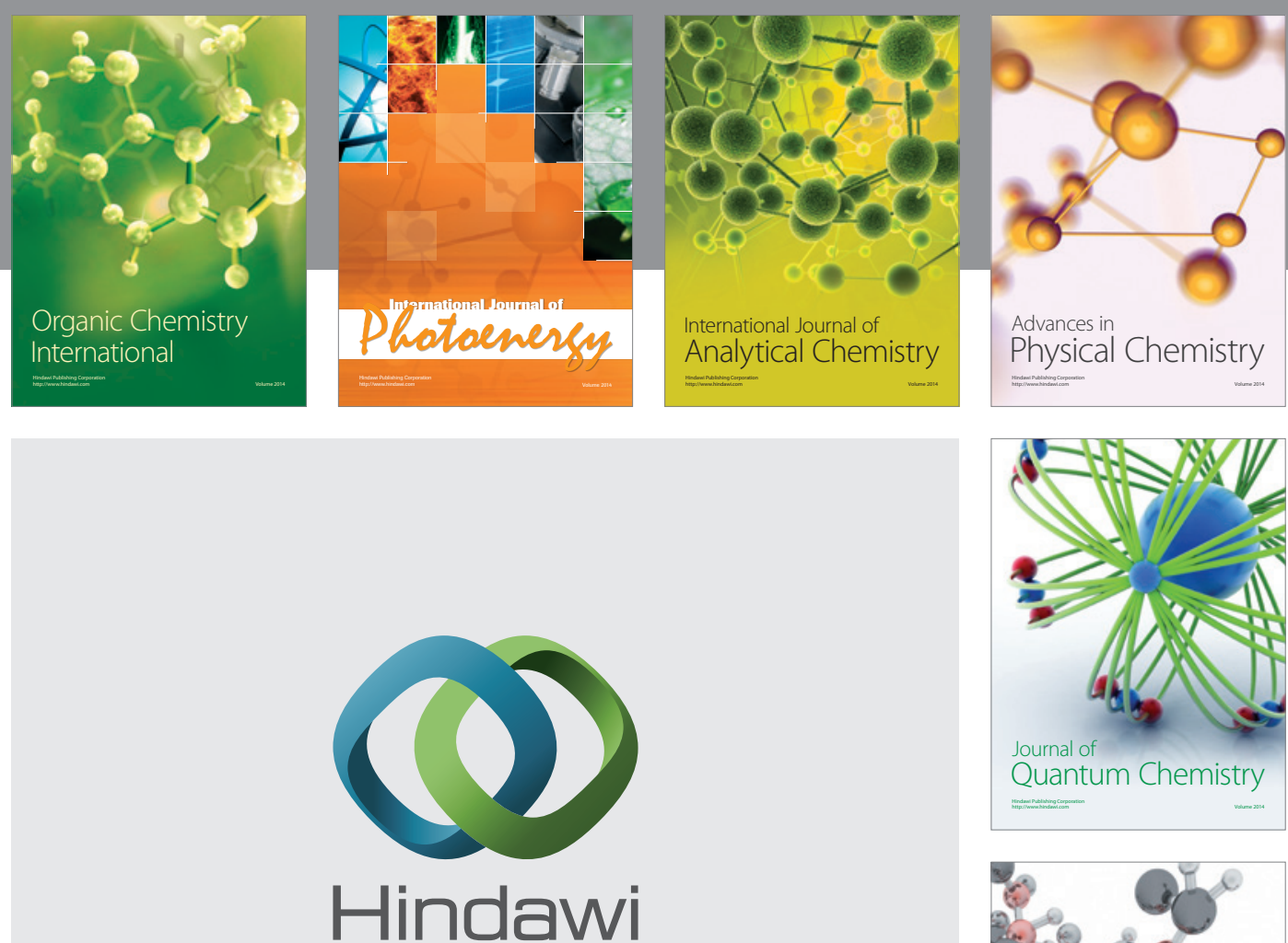

Submit your manuscripts at

http://www.hindawi.com

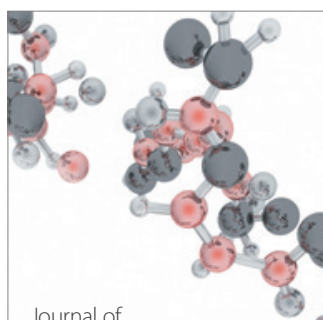

Analytical Methods

in Chemistry

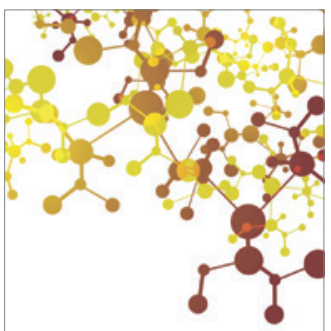

Journal of

Applied Chemistry

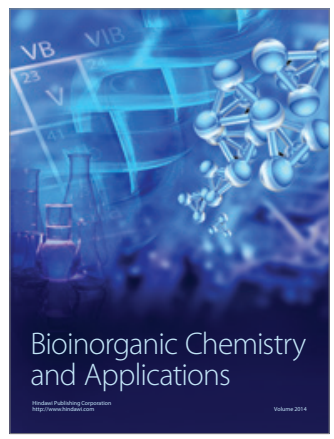

Inorganic Chemistry
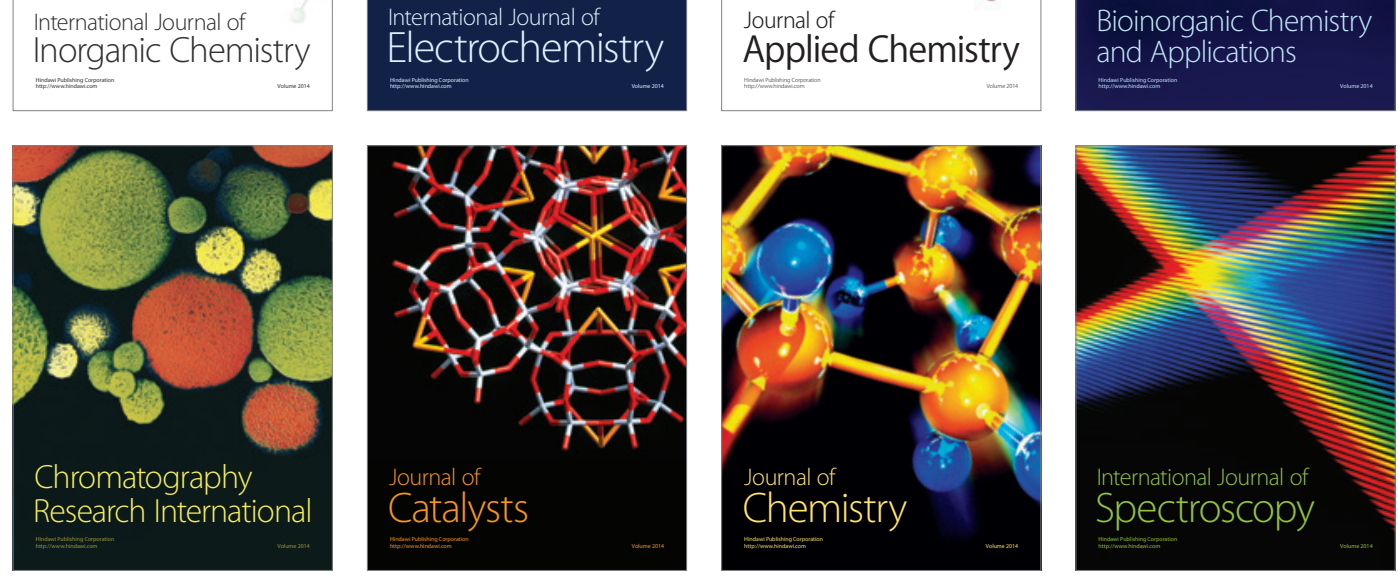